\title{
Multifarious functional traits of free-living rhizospheric fungi, with special reference to Aspergillus spp. isolated from North Indian soil, and their inoculation effect on plant growth
}

Mohd Imran ${ }^{1,2}$, Hussein H. Abulreesh ${ }^{3,4}$ (D) Mohammad K. Monjed ${ }^{3,4}$, Khaled Elbanna ${ }^{3,4,5}$, Samreen ${ }^{1}$ and lqbal Ahmad ${ }^{1,3,4^{*}}$

\begin{abstract}
Purpose: Rhizospheric soil fungi are critical for plant and soil health. However, their multiple functional traits and impact on plant growth have not been systematically explored.

Methods: During this study, biochemical traits of 73 indigenous soil fungal isolates and 15 unidentified isolates related to plant growth promotion and production of extracellular enzymes were studied.

Results: Forty four (65.67\%) of the total isolates produced indole acetic acid (IAA) followed by siderophore (52.23\%), phosphate solubilization (37.31\%), and antibiotic (11.93\%). 91.04\% of the studied isolates produced ammonia whereas $28.35 \%$ produced organic acid. Extracellular enzyme activities of lipase, amylase, chitinase, and cellulase were detected among 95.52\%, 61.11\%, 35.82\%, and 41.79\% isolates, respectively. Based on these activities, 73 fungal isolates were categorized into different biotypes. Quantitative analysis of IAA production and phosphate solubilization was carried out for Aspergillus, Penicillium, and Rhizopus isolates. Aspergillus isolates exhibited varying activities of IAA production and phosphate solubilization. Most of the Aspergillus isolates and some other fungi demonstrated multiple activities. Based on the multiple traits of selected fungal isolates, Aspergillus sp-07, Penicillium sp-03, and Rhizopus sp-02 were further evaluated in different combinations for their inoculation effect on the growth and yield of wheat under field conditions.
\end{abstract}

Conclusions: The results indicated that these isolates could be developed into bio-inoculants to enhance plant growth. The consortium of these three isolates was also found to be compatible and beneficial for plant growth. Keywords: Soil fungi, Plant growth promotion, Indole acetic acid, Phosphate solubilization, Extracellular enzymes

\footnotetext{
* Correspondence: ahmadiqbal8@yahoo.co.in

'Department of Agricultural Microbiology, Faculty of Agricultural Sciences,

Aligarh Muslim University, Aligarh 202002, India

${ }^{3}$ Department of Biology, Faculty of Applied Science, Umm Al-Qura University,

Makkah, Saudi Arabia

Full list of author information is available at the end of the article
}

(c) The Author(s). 2021 Open Access This article is licensed under a Creative Commons Attribution 4.0 International License, which permits use, sharing, adaptation, distribution and reproduction in any medium or format, as long as you give appropriate credit to the original author(s) and the source, provide a link to the Creative Commons licence, and indicate if changes were made. The images or other third party material in this article are included in the article's Creative Commons licence, unless indicated otherwise in a credit line to the material. If material is not included in the article's Creative Commons licence and your intended use is not permitted by statutory regulation or exceeds the permitted use, you will need to obtain permission directly from the copyright holder. To view a copy of this licence, visit http://creativecommons.org/licenses/by/4.0/ 


\section{Background}

Fungi are an integral part of the terrestrial ecosystems and are known for their wide applications in the food, pharmaceutical, agricultural, and health care industries. Soil fungi play an important role in the biogeochemical cycling of the elements, maintaining soil fertility, and humus formation by decomposing organic materials (Frąc et al. 2018; Imran et al. 2020). Phosphate solubilization, nutrient mobilization, metal solubilization, and production of organic acid and extracellular enzymes by fungi have also been reported from different soil niches (Newbound et al. 2010; Frąc et al. 2018). Free-living filamentous soil fungi are diverse, adaptable, and beneficial for plants. They possess the extraordinary ability to degrade complex natural and synthetic organic compounds by producing a wide range of extracellular enzymes (Khalil et al. 2013; Zhao et al. 2014; El-Morsy et al. 2017). Indigenous soil fungi produce different enzymes including amylases, proteases, lipases, pectinases, and cellulases, which are important for industrial utilization (Park et al. 2017; McKelvey and Murphy 2018). These enzymes play vital roles in the soil ecosystem via nutrient turnover and maintaining soil fertility; however, their direct role in promoting plant growth is less explored.

The rhizosphere is a nutrient-rich zone for microorganisms and contains more microbial population density and diversity as compared with bulk soil. Extensive research data have been documented about the relation of mycorrhizal fungi in enhancing plant growth, effect on crop yield, and their significance to the environment (Bona et al. 2017; Carrara et al. 2018; Mohamed et al. 2019). However, such data about free-living rhizospheric soil fungi are limited. Soil bacteria have gained much attention as biofertilizers and biocontrol agents during the last few decades (Hafeez et al. 2006; Bhardwaj et al. 2014; Osman et al. 2015; Singh et al. 2019). The freeliving fungi have yet not been systematically screened for their potential in promoting plant growth. Different species of filamentous fungi have been reported with only one major character such as phosphate solubilization by Aspergillus and Penicillium (Elias et al. 2016). Trichoderma spp. are also known for phosphate-solubilizing properties and have been developed as phosphate solubilizer bioinoculant and biocontrol agent (Li et al. 2015; Shaw et al. 2016).

During this study, we hypothesized that multiple beneficial activities of fungal isolates are distributed among common free-living rhizospheric fungi, and the selection of fungi might enhance plant growth under field conditions. Considering the huge diversity of free-living rhizospheric filamentous fungi and the lack of concerted efforts to screen and utilize the rich diversity of indigenous free-living rhizospheric fungi in promoting plant growth, we used previously isolated rhizospheric fungi from the agricultural fields of Aligarh, Northern India (Imran et al. 2020). During this study, these fungi were further screened for plant growth-promoting traits and extracellular enzyme activities. The isolates with desired traits were also tested in different combinations to assess their potential in promoting plant growth under field conditions.

\section{Materials and methods}

Rhizospheric free-living fungi used in this study

Seventy-three (73) rhizospheric fungi previously isolated from the agricultural fields adjacent to Aligarh city (Northern India) and tentatively identified based on the cultural, morphological, and molecular methods were used in this study. The details of these fungal isolates are available in a recent publication by Imran et al. (2020).

\section{Cultivation of fungi}

The fungal isolates were maintained at $4{ }^{\circ} \mathrm{C}$ in the refrigerator by subculturing on Sabouroud Dextrose Agar (SDA) (Hi-Media Lab. Pvt., Mumbai, India). Fresh fungal cultures for the experiments were prepared by transferring a loop/fragment of mycelium/spore. The purity of freshly grown cultures $\left(28{ }^{\circ} \mathrm{C}\right.$ for 3 to 7 days $)$ was assessed by subsequent streak plate method followed by microscopic examination (Gilman 2001; Zafar and Ahmad 2005; Imran et al. 2020).

\section{Screening of isolates for extracellular enzymes}

All fungal isolates (73) were screened for the production of extracellular enzymes using conventional agar plate assays as follows:

\section{Amylase activity}

Starch-degrading activity of the cultures was estimated by the hydrolysis of starch on a medium $\left(\mathrm{g} \cdot \mathrm{l}^{-1}\right)$ containing 5.0 g peptone, $3.0 \mathrm{~g}$ beef extract, $2.0 \mathrm{~g}$ starch (soluble), and 20 g agar. Freshly grown fungal spores of 3-day-old culture were spot inoculated in the center of the plate and incubated at $28{ }^{\circ} \mathrm{C}$ for 7 days. Seven-day-old fungal cultures were flooded with an iodine solution (Yarrow 1998; Singh et al. 2014). The development of a pale yellow zone around a colony in the blue medium indicated the starchdegrading activity, and isolates were considered positive for amylase production.

\section{Lipase activity}

Fungal isolates were inoculated on tributyrin agar medium (g. $\mathrm{l}^{-1}$ ) containing $5.0 \mathrm{~g}$ peptone, $3.0 \mathrm{~g}$ beef extract, 10 tributyrin, and $15 \mathrm{~g}$ agar at $\mathrm{pH}$ 6.5. The development of a clear halo zone around the colony indicated the lipase activity after incubation at $28{ }^{\circ} \mathrm{C}$ for 7 days (Cappuccino and Welsh 2018). 


\section{Cellulase activity}

Cellulase activity was examined using a modified agarose plate technique. The plates contained the medium $[14 \mathrm{ml}$ of $10 \%\left(\mathrm{NH}_{4}\right)_{2} \mathrm{SO}_{4}, 15 \mathrm{ml}$ of $1 \mathrm{M} \mathrm{KH}_{2} \mathrm{PO}_{4}, 6.0 \mathrm{ml}$ of $35 \%$ urea, $3.0 \mathrm{ml}$ of $10 \% \mathrm{CaCl}_{2}, 3.0 \mathrm{ml}$ of $10 \% \mathrm{MgSO}_{4} \cdot 7 \mathrm{H}_{2} \mathrm{O}, 1.0 \mathrm{ml}$ of trace elements solution $(10 \mathrm{ml}$ of concentrated $\mathrm{HCl}, 0.51 \%$ $\mathrm{FeSO}_{4}, 0.186 \% \mathrm{MnSO}_{4} \cdot 4 \mathrm{H}_{2} \mathrm{O}, 0.166 \% \mathrm{ZnCl}_{2}$, and $0.2 \%$ $\mathrm{CoCl}_{2}$ ), $2.0 \mathrm{ml}$ of Tween $80,0.2 \%$ cellulose, and $1.5 \%$ agarose)] (Mandels et al. 1962; Jahangeer et al. 2005). A single isolate of fungi was inoculated in the middle of the cellulose/ agarose plate and incubated for 7 days at $28{ }^{\circ} \mathrm{C}$. The plates were flooded with $0.1 \%$ Congo red and allowed to react for $30 \mathrm{~min}$ followed by destaining with $1 \mathrm{M} \mathrm{NaCl}$ for $60 \mathrm{~min} \mathrm{ac}-$ cording to Teather and Wood (1982). The width of fungal growth and the zone of clearing indicated the cellulase activity in the cellulose medium.

\section{Chitinase activity}

The production of chitinases was determined on the plates pre-poured with a layer of $15 \mathrm{~g} \cdot \mathrm{l}^{-1}$ agar and successively poured with a $3.0-\mathrm{ml}$ overlayer of the test medium containing $25 \mathrm{gll}^{-1}$ chitin powder (Hi-Media) (Campbell and Williams 1951; Krithika and Chellaram 2016). After incubation at $28{ }^{\circ} \mathrm{C}$ for 7 days, the formation of a clear zone around the colony in an opaque medium indicated the presence of extracellular chitinase.

\section{In vitro detection of plant growth-promoting (PGP) traits of soil fungi}

Plant growth-promoting activities of isolated soil fungi were detected and quantified in vitro. PGP activities such as the production of indole acetic acid, siderophore, antibiotics, ammonia, organic acid, and phosphate solubilization were determined according to the standard methods as follows:

\section{Production and quantification of indole acetic acid (IAA)}

Fungal cultures were grown in Sabouroud Dextrose broth amended with $500 \mu \mathrm{g} \cdot \mathrm{ml}^{-1}$ tryptophan at $28{ }^{\circ} \mathrm{C}$ for 7 days. The fungal growth was separated from 7 -day-old culture by filtration followed by centrifugation at 10,000 rpm for $20 \mathrm{~min}$. Two milliliters of supernatant was taken from each tube and mixed with $4.0 \mathrm{ml}$ of Salkowski's reagent $(50 \mathrm{ml}$ of $35 \%$ perchloric acid, and $1.0 \mathrm{ml}$ of $0.5 \mathrm{M}$ $\mathrm{FeCl}_{3}$ ), and 2-3 drops of orthophosphoric acid were added to each aliquot. The samples were incubated at room temperature for $25 \mathrm{~min}$. The development of the rose pink color indicated the production of IAA (Ahmad et al. 2006). IAA was quantified by reading the Optical Density (OD) at $530 \mathrm{~nm}$ using a Spectronic $20 \mathrm{D}^{+}$spectrophotometer, whereas its concentration was measured through a standard IAA graph ranging from 10 to 100 $\mathrm{mg} / \mathrm{ml}$.

\section{Phosphate solubilization and quantification}

Phosphate solubilization was detected on Pikovskaya agar plates containing $\left(\mathrm{g} \cdot \mathrm{l}^{-1}\right) 10 \mathrm{~g}$ glucose, $5.0 \mathrm{~g}$ tricalcium phosphate, $0.5 \mathrm{~g}$ yeast extract, 0.5 ammonium sulfate, $0.2 \mathrm{~g} \mathrm{MgSO}_{4}, 0.1 \mathrm{~g} \mathrm{NaCl}$, and a trace amount of manganese sulfate and ferrous sulfate according to Ahmad et al. (2006). The fungal cultures were grown on the Pikovskaya agar plates at $28{ }^{\circ} \mathrm{C}$ for 7 days. After the incubation period, a clear halo zone of tricalcium phosphate solubilization around the fungal colony indicated a positive result. The solubilization index was evaluated as the ratio of the total diameter (colony + halo zone) and colony diameter of the test fungi (Premono et al. 1996).

The release of soluble phosphate in the culture medium was measured to quantify the phosphate solubilization according to Gaur (1990). Briefly, the fungal cultures were separately inoculated $\left(2.5 \times 10^{6}\right.$ spore. $\mathrm{ml}^{-1}$ ) in $25 \mathrm{ml}$ of Pikovskaya broth in a 100-ml flask and incubated at $28{ }^{\circ} \mathrm{C}$ and $125 \mathrm{rpm}$ for 7 days. The uninoculated medium with tricalcium phosphate served as the control. The culture was filtered and centrifuged at $10,000 \mathrm{rpm}$ for $30 \mathrm{~min}$, and the $\mathrm{pH}$ of the supernatant was determined. An aliquot of $10 \mathrm{ml}$ supernatant and 10 $\mathrm{ml}$ of chloromolybdic acid were mixed in a separate tube, and 5-6 drops of chlorostannous acid were added. The volume was adjusted to $50 \mathrm{ml}$ with double distilled water and the developed blue color was read at $600 \mathrm{~nm}$. The amount of solubilized phosphate was calculated using the calibration curve of $\mathrm{KH}_{2} \mathrm{PO}_{4}$. Biomass was separately processed to determine its dry weight.

\section{Production of siderophores}

Siderophore production was detected by the $\mathrm{FeCl}_{3}$ test (Jalal and van der Heim 1990). Briefly, 7-day- old culture grown in Sabouroud dextrose broth was filtered through Whatman filter paper (No. 42). Culture filtrate was centrifuged at 10,000 rpm for $20 \mathrm{~min}$. Then, an aliquot of $1.0 \mathrm{ml}$ was taken and $1.0 \mathrm{ml}$ of $2 \%$ aqueous ferric chloride solution was added. The formation of reddish brown or red color indicated the siderophore production. Uninoculated SD broth was used as a negative control.

\section{Production of organic acid}

The Sabouroud dextrose agar media amended with $2 \%$ alizarin red $\mathrm{S}$ dye was used to examine the production of organic acid. Both media and Alizarin red S were separately autoclaved and mixed in molten media $\left(50{ }^{\circ} \mathrm{C}\right)$ before plates were poured. Spore suspension of different fungal isolates was spot inoculated in the center and incubated at $28 \pm 2{ }^{\circ} \mathrm{C}$ for 7 days. Medium acidification was visualized by the presence of $\mathrm{pH}$ indicator Alizarin red $\mathrm{S}$, whereas the diameter of the yellow (acid) zone or change in color from red to yellow around the fungal 
colony indicated the production of organic acid (Prusky et al. 2001).

\section{Production of ammonia}

Ammonia production was detected in peptone water (Hi-Media). Fungal cultures were inoculated and incubated at $28{ }^{\circ} \mathrm{C}$ for 7 days. After incubation, $1.0 \mathrm{ml}$ of Nessler's reagent was added to each tube, and the development of brown to the yellow color indicated the positive test (Cappuccino and Welsh 2018).

\section{Antibiotic activity of fungal culture filtrates}

A modified agar well diffusion method was adopted to determine the antibacterial activity of fungal culture filtrates (Ahmad and Beg 2001). An aliquot of $0.1 \mathrm{ml}$ was grown overnight at $37^{\circ} \mathrm{C}$ and appropriately diluted cultures $\left(10^{5} \mathrm{CFU} \cdot \mathrm{ml}^{-1}\right)$ of Escherichia coli and Staphylococcus aureus were spread on Muller-Hinton Agar (HiMedia) plates. The wells of $8.0 \mathrm{~mm}$ diameter were punched into agar medium and filled with $100 \mu \mathrm{l}$ of fungal culture filtrates obtained from 7-day-old culture. The plates were incubated at $37{ }^{\circ} \mathrm{C}$ for $18-24 \mathrm{hrs}$. Antibiotic (chloramphenicol) concentration of $100 \mu \mathrm{g} \cdot \mathrm{ml}^{-1}$ was used as the positive control. The zones of inhibition for bacterial growth were measured in millimeters around each well.

\section{The role of soil fungi in promoting Wheat (Triticum aestivum) plant growth under field conditions}

The field experiments were carried out on wheat (Triticum aestivum) var. PBW 343, at the Agricultural fields of Faculty of Agricultural Sciences, Aligarh Muslim University, Aligarh, India. Wheat seeds were sown in 12 plots by following a completely randomized design. Crops were irrigated with tube-well water by drip irrigation.

\section{Inoculum and plant culture}

The plant growth-promoting fungal isolates (Aspergillus niger, Asp-07), Penicillium sp-03, and Rhizopus oryzae, Rsp-02) were cultured on Sabouraud dextrose agar plates at $30{ }^{\circ} \mathrm{C}$. The spores were scraped from the plates with a pasture pipette by using $2.0 \mathrm{ml}$ sterile normal saline solution and transferred to a sterile test tube. The concentration of the spores was adjusted to $1 \times 10^{6}$ spore. $\mathrm{ml}^{-1}$. The consortium of Aspergillus niger, Penicillium sp-03, and Rhizopus oryzae (Table 1) were prepared by adding equal volumes of spore suspensions of all the strains. Then, the surface-sterilized seeds were either soaked in the individual suspensions or consortium suspension for $2 \mathrm{~h}$ at $28{ }^{\circ} \mathrm{C}$ on a shaker. The seeds were soaked in $0.85 \%$ normal saline solution for minimum dose treatment of inorganic fertilizers (NPK and DAP) and controls (Table 1). The seeds of each treatment were kept in $10 \mathrm{ml}$ sterile NSS to assess the CFU/seed of the inoculated fungi on agar media. Control seeds (uninoculated) were surface sterilized by treating with mercuric chloride $(0.1 \%)$. Then, control seeds were soaked in $0.85 \%$ saline followed by three-time washing with sterile distilled water before sowing. The experimental scheme is summarized in Table 1.

Inoculum density on the seeds was determined by agitating ten seeds from each treatment in $10 \mathrm{ml}$ sterile NSS that was plated on agar plates after serial dilution. Mean fungal spore density per seed was determined after 4 days of incubation at $28 \pm 2{ }^{\circ} \mathrm{C}$.

\section{Harvesting and data collection}

The wheat sampling was carried out at 50 DAS (vegetative), 70 DAS (flowering), and harvesting. The plants were randomly removed from each treatment during the sampling. Plants were extended and pressed for

Table 1 Different sowing treatments of Triticum aestivum var PBW 343

\begin{tabular}{lll}
\hline Treatment no. & Description of treatments & Types of treatments \\
\hline$T_{C}$ & Control & Uninoculated and unfertilized \\
$T_{F}$ & NPK & Uninoculated (Inorganic fertilizer dose) \\
$T_{1}$ & NPK + Aspergillus niger(Asp-07) & Single fungal inoculation with NPK \\
$T_{2}$ & NPK + Penicillium sp-03 & Single fungal inoculation with NPK \\
$T_{3}$ & NPK + Rhizopus oryzae(Rsp02) & Single fungal inoculation with NPK \\
$T_{4}$ & Aspergillus niger & Single fungal inoculation \\
$T_{5}$ & Penicillium sp-03 & Single fungal inoculation \\
$T_{6}$ & Rhizopus oryzae & Single fungal inoculation \\
$T_{7}$ & Aspergillus niger + Penicillium sp-03 & Dual fungal inoculation \\
$T_{8}$ & Aspergillus niger + Rhizopus oryzae & Dual fungal inoculation \\
$T_{9}$ & Penicillium sp-3 + Rhizopus oryzae & Dual fungal inoculation \\
$T_{10}$ & Aspergillus niger + Penicillium sp-03 + Rhizopus oryzae & Triple fungal inoculation \\
\hline
\end{tabular}

$N$ nitrogen, $P$ phosphate, $K$ potassium 
biometric analysis. The following growth and yield parameters were determined using standard methods.

\section{Vegetative growth parameters}

The wheat plant growth parameters such as shoot weight, shoot length, leaf numbers, Spikelet numbers, and other parameters were taken into account at three stages (50, 70, and $130 \mathrm{DAS})$.

\section{Estimation of nitrogen content}

Nitrogen content was estimated according to Lindner and Harley (1942). Dry plant material $(1.0 \mathrm{~g})$ was digested in concentrated $\mathrm{H}_{2} \mathrm{SO}_{4}$ and $30 \% \mathrm{H}_{2} \mathrm{O}_{2}$. A $10-\mathrm{ml}$ aliquot of the digested material was added to a $50-\mathrm{ml}$ flask. Two milliliters of $2.5 \mathrm{~N}$ sodium hydroxide was added into the flask to neutralize the excess acid, and $2.0 \mathrm{ml}$ of sodium salicylate was added to prevent the turbidity. The volume of the solution was made up to the mark. An aliquot of $5.0 \mathrm{ml}$ of this solution was taken, and $0.5 \mathrm{ml}$ Nessler's reagent was added to it. The volume was made up to $10 \mathrm{ml}$ with distilled water and allowed to stand for $5 \mathrm{~min}$. Absorbance was read at 525 $\mathrm{nm}$, whereas the standard curve was prepared by using ammonium sulfate solution.

\section{Estimation of protein content}

The protein content of wheat seeds was estimated according to Lowry et al. (1951). Briefly, $500 \mathrm{mg}$ of the seeds soaked in PBS were finely ground in 5-10 ml PBS. The resultant sample extract was centrifuged, and the supernatant was used for protein estimation. Aliquots of 0.1 and $0.2 \mathrm{ml}$ were taken from the sample extract, and the volume was made up to $1.0 \mathrm{ml}$. A tube containing $1.0 \mathrm{ml}$ of water served as a blank. Five milliliters of copper solution was mixed into each tube including the blank. The contents were mixed well and allowed to stand for $10 \mathrm{~min}$. A $0.5-\mathrm{ml}$ aliquot of Folin's reagent was added to the mixture and incubated at room temperature for $30 \mathrm{~min}$. The OD was read at $660 \mathrm{~nm}$ after the development of blue color. The standard curve of bovine serum albumin (BSA) solution was used to calculate the protein concentration as milligram per gram $\left(\mathrm{mg} \cdot \mathrm{g}^{-1}\right)$ of seed.

\section{Yield parameters}

The yield parameters were studied at the time of harvesting including the weight of seeds per plant and weight of thousand seeds.

\section{Statistical analysis}

The experimental data were subjected to statistical analysis using Duncan's new multiple range test (MRT). The differences among means were calculated at $P<0.05$.

\section{Results}

During this study, previously isolated fungal isolates (73) belonging to various genera including Aspergillus, Curvularia, Penicillium, Rhizopus, and Mucor (Imran et al. 2020) were screened for their potential in producing extracellular enzymes and plant growth-promoting activities. The study included 20 distinct isolates of Aspergillus followed by Curvularia (09), Mycelia Sterillia (05), and Penicillium (03), whereas the remaining 14 genera were represented by one or two isolates. Fifteen unidentified isolates were also included in the primary screening.

Screening of fungal isolates for extracellular enzyme and plant growth-promoting (PGP) activities

The production of extracellular enzymes by 73 fungal isolates is shown in Table 2. Lipase was the most frequently produced enzyme by 70 fungal isolates $(95.89 \%)$ followed by amylase which was produced by 45 isolates (61.64\%). The production of chitinase and cellulose was observed in 27 (36.98\%), and 30 (41.09\%) fungal isolates, respectively (Table 2). The majority of the isolates produced more than one enzyme, while Mucor spp. and Trichothecium could not produce any enzyme (Table 2). The production of lipase and amylase was observed in the majority of the Aspergillus isolates [20 (100\%, $n=$ $20)$, and $16(80 \%, n=20)$ isolates, respectively]. However, only a few isolates were able to produce both chitinase and cellulose $(40 \%, n=20)$ enzymes (Table 2$)$.

Free-living rhizospheric soil fungal isolates exhibited varying plant growth-promoting activities (Table 3). Sixty-one $(83.56 \%)$ isolates out of the total 73 were found positive for ammonia production, the most frequently detected trait followed by the production of indole acetic acid (IAA) in 44 (60.27\%) isolates. Siderophore production was observed in 35 (47.94\%) isolates followed by the detection of phosphate solubilization in 25 (34.25\%) isolates. 26.02\% (19) isolates produced organic acid, whereas only $10.95 \%$ (8) isolates could produce antibiotics. The production of ammonia (60\%), IAA (50\%), and siderophore (40\%) were the most frequently detected plant growth-promoting traits in Aspergillus isolates $(n=20)$ (Table 3$)$. The overall enzyme and PGP activities of Aspergillus isolates are presented in Table 4.

\section{Assessment of plant growth-promoting activities of soil fungi on solid media \\ Phosphate solubilization and production of organic acid}

The phosphate-solubilizing activity of fungal isolates was determined on Pikovskaya agar plates, and efficient isolates were identified. The maximum phosphate solubilization activity among Aspergillus isolates was observed in Aspergillus sp-01 ( $\mathrm{SI}=2.40)$ followed by 
Table 2 Extracellular enzyme activities of 73 free-living rhizospheric fungi

\begin{tabular}{|c|c|c|c|c|}
\hline \multirow[t]{2}{*}{ Fungal isolates $(n)$} & \multicolumn{4}{|c|}{ Number of positive isolates (\%) for Enzyme activities } \\
\hline & Lipase & Amylase & Chitinase & Cellulase \\
\hline Alternaria (2 isolates) & $2(100)$ & $2(100)$ & $2(100)$ & ND \\
\hline Aspergillus (20 isolates) & $20(100)$ & $16(80)$ & $8(40)$ & $8(40)$ \\
\hline Chlamydospora (1 isolate) & $1(100)$ & ND & ND & ND \\
\hline Curvularia (9 isolates) & $9(100)$ & $5(55.5)$ & $2(22.2)$ & $5(55.5)$ \\
\hline Fusarium (1 isolates) & $1(100)$ & ND & $1(100)$ & $1(100)$ \\
\hline Hormodendrum (1 isolate) & $1(100)$ & $1(100)$ & ND & ND \\
\hline Microsporum (2 isolates) & $2(100)$ & $1(50)$ & $1(50)$ & ND \\
\hline Monilia (2 isolates) & $2(100)$ & $1(50)$ & $1(50)$ & $2(100)$ \\
\hline Monotospora (2 isolates) & $2(100)$ & $2(100)$ & $2(100)$ & $1(50)$ \\
\hline Mucor (1 isolate) & ND & ND & ND & ND \\
\hline Nigrospora (1 isolates) & $1(100)$ & $1(100)$ & ND & ND \\
\hline Penicillium (3 isolates) & $3(100)$ & $2(66.6)$ & ND & ND \\
\hline Rhizopus (2 isolates) & $1(50)$ & ND & $1(50)$ & ND \\
\hline Trichoderma (2 isolates) & $2(100)$ & $1(50)$ & ND & $1(50)$ \\
\hline Trichophyton (2 isolates) & $2(100)$ & $1(50)$ & ND & $1(50)$ \\
\hline Trichothecium (1 isolate) & ND & ND & ND & ND \\
\hline Verticillium (1 isolate) & $1(100)$ & ND & ND & ND \\
\hline Mycelia sterillia (5 isolates) & $5(100)$ & $3(6)$ & $5(100)$ & $3(60)$ \\
\hline Unidentified (15 isolates) & $15(100)$ & $9(60)$ & $4(26.6)$ & $8(53.3)$ \\
\hline \multicolumn{5}{|l|}{ Total number of isolates (73) } \\
\hline Enzyme-producing isolates, total no. (\%) & $70(95.89 \%)$ & 45 (61.64\%) & 27 (36.98\%) & $30(41.09 \%)$ \\
\hline
\end{tabular}

$n$ number of isolates of each identified genera

$P$ positive isolates for enzyme production, $(\%)=$ percentage of positive isolates ND not detected

Aspergillus sp-03 $(\mathrm{SI}=2.29)$. A few isolates belonging to other fungal genera also exhibited efficient phosphate solubilization on solid agar medium including Mucor sp$01(\mathrm{SI}=2.57)$, Penicillium sp-03 $(\mathrm{SI}=2.53)$, Alternaria sp-01 (SI = 2.33), Curvularia sp-02 (SI = 2.36), and other species (Table 5).

The production of organic acid was tested on SDA agar plates amended with Alizarin dye. The halo yellow zones around the fungal colonies were measured for the production of organic acid. Fungal isolates such as Aspergillus sp-07 $(\mathrm{SI}=2.30)$, Alternaria $\mathrm{sp}-02(\mathrm{SI}=2.35)$, Mycelia sterilia sp-01(SI = 2.66), and Unidentified sp-07 $(\mathrm{SI}=2.33)$ efficiently produced organic acid. However, the Unidentified sp-03 $(\mathrm{SI}=2.69)$ isolate remained the best producer of organic acid among all tested isolates (Table 5).

The fungal isolates were grouped into 10 PGP groups/ types based on the presence or absence of one or more PGP traits such as phosphate solubilization and production of IAA, ammonia, and siderophore. Group I consisting of 12 isolates (Aspergillus sp-01, Aspergillus sp-02 .,Alternaria, Curvularia, Fusarium, Mucor, Penicillium, Rhizopus, Trichoderma, and three unidentified spp (sp-
02, sp-10, and sp-14)) possessed all four PGP traits as shown in Table 6.

\section{Quantitative assessment of plant growth-promoting} activities and biomass production in liquid medium Based on the multiple PGP traits, certain isolates belonging to different fungal genera were analyzed for the quantification of phosphate solubilization and IAA production. These isolates were Aspergillus (sp-01), Aspergillus (sp-02), Aspergillus (sp-03), Aspergillus (sp-04), Aspergillus (sp-05), Aspergillus (sp-06), Aspergillus (sp07), Aspergillus (sp-16), Aspergillus (sp-17), Alternaria (sp-01), Curvularia (sp-02), Fusarium (sp-01), Penicillium (sp-03), and Rhizopus (sp-02).

\section{Phosphate solubilization and biomass production}

Fungal isolates were grown in Pikorsvkaya broth for 7 days to estimate the solubilized phosphate. The maximum tricalcium phosphate (TCP) solubilization (435 $\mu \mathrm{g} \cdot \mathrm{ml}^{-1}$ ) activity among tested Aspergillus isolates was exhibited by Aspergillus sp-07 followed by Aspergillus sp-06 $\left(322 \mu \mathrm{g} \cdot \mathrm{ml}^{-1}\right)$. The maximum TCP solubilization among the fungal isolates of other genera was observed 
Table 3 Plant growth-promoting activities of free-living rhizospheric fungi

\begin{tabular}{|c|c|c|c|c|c|c|}
\hline \multirow[t]{2}{*}{ Fungal isolates $(n)$} & \multicolumn{6}{|c|}{ Plant growth-promoting activities } \\
\hline & IAA production & $\mathrm{PO}_{4}$ solubilization & Organic acids & Siderophore & $\mathrm{NH}_{3}$ & Antibiotic production \\
\hline Alternaria (2 isolates) & $1(50)$ & $2(100)$ & $2(100)$ & $2(100)$ & $2(100)$ & ND \\
\hline Aspergillus (20 isolates) & $10(50)$ & $6(30)$ & $5(25)$ & $8(40)$ & $12(60)$ & $1(5)$ \\
\hline Chlamydospora (1) & $1(100)$ & ND & ND & $1(100)$ & $1(100)$ & $1(100)$ \\
\hline Curvularia (9) & $2(22.2)$ & $3(33.3)$ & ND & $5(55.5)$ & $8(88.8)$ & $1(11.1)$ \\
\hline Fusarium (1) & $1(100)$ & ND & $1(100)$ & ND & $1(100)$ & ND \\
\hline Hormodendrum (1) & $1(100)$ & $1(100)$ & ND & $1(100)$ & $1(100)$ & ND \\
\hline Mycellia sterillia (5) & $4(80)$ & ND & $1(20)$ & $2(40)$ & $5(100)$ & ND \\
\hline Microsporum (2) & $2(100)$ & $1(50)$ & ND & ND & $2(100)$ & ND \\
\hline Monilia (2) & ND & ND & ND & ND & $2(100)$ & ND \\
\hline Monotospora (2) & $1(50)$ & $1(50)$ & $1(50)$ & $2(100)$ & $2(100)$ & ND \\
\hline Mucor (1) & $1(100)$ & $1(100)$ & ND & $1(100)$ & $1(100)$ & ND \\
\hline Nigrospora (1) & $1(100)$ & ND & ND & ND & $1(100)$ & $1(100)$ \\
\hline Penicillium (3) & $1(33.3)$ & $1(33.3)$ & ND & $2(66.6)$ & $3(100)$ & ND \\
\hline Rhizopus (2) & $1(50)$ & ND & $1(50)$ & ND & $1(50)$ & ND \\
\hline Trichoderma (2) & $1(50)$ & $1(50)$ & $1(50)$ & $2(100)$ & $2(100)$ & ND \\
\hline Trichophyton (2) & $2(100)$ & $2(100)$ & ND & ND & $2(100)$ & ND \\
\hline Trichothecium (1) & $1(100)$ & ND & $1(100)$ & $1(100)$ & $1(100)$ & $1(100)$ \\
\hline Verticillium (1) & $1(100)$ & $1(100)$ & $1(100)$ & ND & $1(100)$ & ND \\
\hline Unidentified fungi (15) & $12(80)$ & $5(33.3)$ & $6(40)$ & $8(53.3)$ & $13(86.6)$ & $3(20)$ \\
\hline \multicolumn{7}{|l|}{ Total number of fungal isolates (73) } \\
\hline Total number (\%) of positive isolates & $44(60.27)$ & $25(34.25)$ & $19(26.02)$ & $35(47.94)$ & $61(83.56)$ & $8(10.95)$ \\
\hline
\end{tabular}

$N D$ not detected

In parenthesis, percentage of the number of isolates among the total positive fungal isolates is given.

Table 4 Multiple plant growth-promoting activities of Aspergillus isolates

\begin{tabular}{|c|c|c|c|c|c|c|c|c|c|c|}
\hline $\begin{array}{l}\text { Aspergillus } \\
\text { isolates }\end{array}$ & $\begin{array}{l}\text { Phosphate } \\
\text { solubilization }\end{array}$ & $\begin{array}{l}\text { Organic } \\
\text { acid }\end{array}$ & Siderophore & $\mathrm{NH} 3$ & $\begin{array}{l}\text { Antibiotic } \\
\text { production }\end{array}$ & Lipase & Amylase & Chitinase & Cellulase & IAA \\
\hline Asp-01 & + & - & + & + & - & + & + & - & - & + \\
\hline Asp-02 & + & + & - & + & - & + & + & + & - & + \\
\hline Asp-03 & - & + & - & + & - & + & + & - & - & + \\
\hline Asp-04 & + & - & - & + & - & + & + & + & - & + \\
\hline Asp-05 & + & - & + & - & - & + & + & + & - & + \\
\hline Asp-06 & + & + & - & + & - & + & + & - & + & + \\
\hline Asp-07 & + & + & + & - & - & + & + & - & + & + \\
\hline Asp-08 & - & - & + & + & - & + & + & + & + & - \\
\hline Asp-09 & - & - & - & + & + & + & - & - & - & - \\
\hline Asp-10 & - & + & + & + & - & + & - & - & + & + \\
\hline Asp-11 & - & - & + & + & - & + & + & - & - & - \\
\hline Asp-12 & - & - & + & + & - & + & + & - & + & - \\
\hline Asp-13 & - & - & - & + & - & + & + & - & - & + \\
\hline Asp-14 & - & - & + & + & - & + & + & + & - & + \\
\hline Total (\%) & $6(42.85)$ & $5(35.71)$ & $8(57.14)$ & $\begin{array}{l}12 \\
(85.71)\end{array}$ & $1(7.14)$ & $100 \%$ & $\begin{array}{l}12 \\
(85.71)\end{array}$ & $5(35.71)$ & $5(35.71)$ & $\begin{array}{l}10 \\
(71.42)\end{array}$ \\
\hline
\end{tabular}


Table 5 Phosphate solubilization and organic acid production capability of soil fungal isolates

\begin{tabular}{|c|c|c|c|c|c|c|}
\hline \multirow[t]{2}{*}{ Isolates } & \multicolumn{3}{|c|}{ Phosphate solubilization } & \multicolumn{3}{|c|}{ Organic acid production } \\
\hline & $\begin{array}{l}\text { Colony diameter } \\
(\mathrm{mm})\end{array}$ & $\begin{array}{l}\text { Halo zone } \\
(\mathrm{mm})\end{array}$ & $\begin{array}{l}\text { Solubilization index } \\
\text { (SI) }\end{array}$ & $\begin{array}{l}\text { Colony diameter } \\
(\mathrm{mm})\end{array}$ & $\begin{array}{l}\text { Halo zone } \\
(\mathrm{mm})\end{array}$ & $\begin{array}{l}\text { Solubilization index } \\
\text { (SI) }\end{array}$ \\
\hline Aspergillus sp-01 & $10 \pm 0.65$ & $14 \pm 0.78$ & $2.40 \pm 0.09$ & + & - & - \\
\hline Aspergillus sp-02 & $19 \pm 0.98$ & $24 \pm 1.0$ & $2.26 \pm 0.14$ & $21 \pm 1.2$ & $25 \pm 1.6$ & $2.19 \pm 0.12$ \\
\hline Aspergillus sp-03 & $17 \pm 0.74$ & $22 \pm 0.99$ & $2.29 \pm 0.16$ & + & - & - \\
\hline Aspergillus sp-04 & $15 \pm 0.68$ & $18 \pm 0.95$ & $2.20 \pm 0.10$ & + & - & - \\
\hline Aspergillus sp-05 & $15 \pm 0.71$ & $17 \pm 0.78$ & $2.13 \pm 0.08$ & + & - & - \\
\hline Aspergillus sp-06 & $18 \pm 0.89$ & $21 \pm 0.89$ & $2.16 \pm 0.07$ & $24 \pm 1.4$ & $29 \pm 1.8$ & $2.20 \pm 1.13$ \\
\hline Aspergillus sp-07 & $26 \pm 1.5$ & $33 \pm 1.9$ & $2.26 \pm 0.15$ & $23 \pm 1.3$ & $30 \pm 2.0$ & $2.30 \pm 0.15$ \\
\hline Aspergillus sp-10 & + & - & - & $14 \pm 0.80$ & $16 \pm 0.86$ & $2.14 \pm 0.10$ \\
\hline Aspergillus sp-16 & $20 \pm 0.96$ & $23 \pm 1.2$ & $2.15 \pm 0.06$ & $17 \pm 0.89$ & $19 \pm 0.96$ & $2.11 \pm 0.09$ \\
\hline Aspergillus sp-17 & $19 \pm 0.86$ & $21 \pm 1.1$ & $2.10 \pm 0.08$ & $18 \pm 0.98$ & $21 \pm 0.99$ & $2.16 \pm 0.08$ \\
\hline Alternaria sp-01 & $12 \pm 0.9$ & $16 \pm 1.1$ & $2.33 \pm 0.13$ & $18 \pm 0.94$ & $21 \pm 0.96$ & $2.16 \pm 0.07$ \\
\hline Alternaria sp-02 & $15 \pm 1.1$ & $20 \pm 1.7$ & $2.33 \pm 0.11$ & $17 \pm 0.82$ & $23 \pm 0.99$ & $2.35 \pm 0.12$ \\
\hline Curvularia sp-02 & $19 \pm 0.1 .3$ & $26 \pm 2.0$ & $2.36 \pm 0.15$ & + & - & - \\
\hline Curvularia sp-03 & $17 \pm 1.0$ & $23 \pm 1.5$ & $2.35 \pm 0.10$ & + & - & - \\
\hline Curvularia sp-06 & $21 \pm 1.4$ & $26 \pm 1.8$ & $2.23 \pm 0.14$ & + & - & - \\
\hline Fusarium sp-01 & $22 \pm 1.5$ & $27 \pm 1.6$ & $2.22 \pm 0.12$ & $16 \pm 0.85$ & $20 \pm 0.88$ & $2.25 \pm 0.06$ \\
\hline $\begin{array}{l}\text { Hormodendrum sp- } \\
01\end{array}$ & $25 \pm 1.8$ & $33 \pm 2.1$ & $2.32 \pm 0.15$ & + & - & - \\
\hline Microsporum sp-01 & $16 \pm 1.2$ & $21 \pm 1.3$ & $2.31 \pm 0.10$ & + & - & - \\
\hline Monotospora sp-01 & $10 \pm 0.8$ & $14 \pm 0.7$ & $2.40 \pm 0.16$ & $24 \pm 0.90$ & $26 \pm 1.3$ & $1.66 \pm 0.07$ \\
\hline $\begin{array}{l}\text { Mycelia Sterilia sp- } \\
01\end{array}$ & + & - & - & $15 \pm 0.65$ & $25 \pm 1.1$ & $2.66 \pm 0.11$ \\
\hline Mucor sp-01 & $14 \pm 0.9$ & $22 \pm 1.5$ & $2.57 \pm 0.13$ & + & - & - \\
\hline Penicillium sp-02 & $15 \pm 0.8$ & $23 \pm 1.4$ & $2.53 \pm 0.13$ & + & - & - \\
\hline Penicillium sp-03 & $13 \pm 1.0$ & $18 \pm 1.1$ & $2.38 \pm 0.11$ & + & - & - \\
\hline Rhizopus sp-02 & $14 \pm 1.1$ & $20 \pm 1.3$ & $2.42 \pm 0.15$ & $18 \pm 0.78$ & $22 \pm 1.0$ & $2.22 \pm 0.08$ \\
\hline Trichoderma sp-01 & $16 \pm 1.2$ & $20 \pm 1.2$ & $2.25 \pm 0.15$ & $26 \pm 1.2$ & $29 \pm 1.5$ & $2.11 \pm 0.09$ \\
\hline Trichophyton sp-01 & $24 \pm 1.7$ & $30 \pm 2.0$ & $2.25 \pm 0.09$ & + & - & - \\
\hline Trichophyton sp-02 & $23 \pm 1.3$ & $32 \pm 2.3$ & $2.34 \pm 0.14$ & + & - & - \\
\hline Trichothecium sp-01 & + & - & - & $15 \pm 0.79$ & $20 \pm 0.96$ & $2.33 \pm 0.10$ \\
\hline Verticillium sp-01 & $25 \pm 1.5$ & $30 \pm 1.9$ & $2.20 \pm 0.10$ & $17 \pm 0.95$ & $20 \pm 0.98$ & $2.17 \pm 0.09$ \\
\hline Unidentified sp-02 & $14 \pm 0.8$ & $21 \pm 1.0$ & $2.50 \pm 0.08$ & $29 \pm 1.4$ & $36 \pm 2.0$ & $2.24 \pm 0.07$ \\
\hline Unidentified sp-03 & $15 \pm 0.7$ & $21 \pm 1.3$ & $2.40 \pm 0.07$ & $13 \pm 0.52$ & $22 \pm 1.4$ & $2.69 \pm 0.13$ \\
\hline Unidentified sp-06 & + & - & - & $13 \pm 0.55$ & $15 \pm 0.66$ & $2.15 \pm 0.09$ \\
\hline Unidentified sp-07 & + & - & - & $18 \pm 0.87$ & $24 \pm 0.98$ & $2.33 \pm 0.13$ \\
\hline Unidentified sp-08 & $10 \pm 0.6$ & $16 \pm 0.8$ & $2.60 \pm 0.15$ & $14 \pm 0.50$ & $17 \pm 0.78$ & $2.21 \pm 0.08$ \\
\hline Unidentified sp-10 & $16 \pm 1.0$ & $23 \pm 1.5$ & $2.43 \pm 0.13$ & + & - & - \\
\hline Unidentified sp-13 & + & - & - & $25 \pm 1.6$ & $32 \pm 2.1$ & $2.28 \pm 0.09$ \\
\hline Unidentified sp-14 & $18 \pm 1.2$ & $24 \pm 1.4$ & $2.33 \pm 0.11$ & + & - & - \\
\hline
\end{tabular}

+ indicates the presence of fungal growth

- indicates no solubilization zone; \pm indicates SD of three replicates 
Table 6 PGP typing of fungal isolates understudy

\begin{tabular}{|c|c|c|c|c|c|c|}
\hline \multirow{2}{*}{$\begin{array}{l}\text { PGP } \\
\text { types }\end{array}$} & \multicolumn{4}{|c|}{ Plant growth-promoting activities } & \multirow[t]{2}{*}{ Isolate designation } & \multirow{2}{*}{$\begin{array}{l}\text { Total } \\
\text { numbe }\end{array}$} \\
\hline & $\begin{array}{l}\text { Phosphate } \\
\text { solubilization }\end{array}$ & IAA & Siderophore & Ammonia & & \\
\hline $\mathrm{I}$ & + & + & + & ++ & $\begin{array}{l}\text { Aspergillus sp-01 and sp-03; Alternaria sp-01; Curvularia sp-02; Fusarium sp-01; } \\
\text { Mucor sp-01; Penicillium sp-03; Rhizopus sp-02; Trichoderma sp-01; Unidentified sp- } \\
02, \mathrm{sp}-10 \text {, and sp-14 }\end{array}$ & 12 \\
\hline$\|$ & - & + & + & + & $\begin{array}{l}\text { Aspergillus sp-14; Chlamydospora sp-01; Curvularia sp-04; Mycelia sterillia sp-01; Tri- } \\
\text { chothecium sp-01; Unidentified sp-04, sp-05, and sp-15 }\end{array}$ & 8 \\
\hline III & + & - & + & ++ & Alternaria sp-02, Monotospora sp-01 & 2 \\
\hline IV & - & - & + & ++ & $\begin{array}{l}\text { Aspergillus sp-08, sp-11, sp-12, and sp-18, Curvularia sp-07 and sp-09; Monotospora } \\
\text { sp-02; Mycelia sterillia sp-02; Penicillium sp-01; Trichoderma sp-02 }\end{array}$ & 10 \\
\hline V & - & - & - & + & $\begin{array}{l}\text { Aspergillus sp-09; Curvularia sp-01 and sp-08; Monilia sp-01; Unidentified sp-06 and } \\
\text { sp-07 }\end{array}$ & 6 \\
\hline $\mathrm{Vl}$ & + & - & - & ++ & Aspergillus sp-16 and sp-17, Curvularia sp-03 and sp-06, Monilia sp-02 & 5 \\
\hline VII & - & - & + & - & Curvularia sp-05, Unidentified sp-12 & 2 \\
\hline VIII & + & + & - & ++ & $\begin{array}{l}\text { Aspergillus sp-04, sp-02, and sp-06; Hormodendrum sp-01; Microsporum sp-01; Peni- } \\
\text { cillium sp-02; Trichophyton sp-01 and sp-02; Unidentified sp-03; Verticillium sp-01 }\end{array}$ & 10 \\
\hline IX & - & + & - & + & $\begin{array}{l}\text { Aspergillus sp-10 and sp-13; Microsprum sp-02; Mycellia sterillia sp-03, sp-04, and } \\
\text { sp-05; Nigrospora sp-01; Rhizopus sp-01; Unidentified sp-01, sp-09, sp-11, and sp-13 }\end{array}$ & 12 \\
\hline$x$ & + & + & + & - & Aspergillus sp-05 and sp-07; Unidentified sp-08 & 3 \\
\hline
\end{tabular}

in Alternaria sp-01 (465 $\left.\mu \mathrm{g} \cdot \mathrm{ml}^{-1}\right)$ followed by Fusarium sp-01 (375 $\left.\mu \mathrm{g} \cdot \mathrm{ml}^{-1}\right)$, Rhizopus sp-02 $\left(320 \mu \mathrm{g} \cdot \mathrm{ml}^{-1}\right)$, Cuvularia sp-02 (295 $\left.\mu \mathrm{g} \cdot \mathrm{ml}^{-1}\right)$, and Penicillium sp-03 (263 $\mu \mathrm{g} \cdot \mathrm{ml}^{-1}$ ) (Table 7).

During the phosphate solubilization, the biomass production of Aspergillus isolates ranged between 0.53 and $0.28 \mathrm{~g} .100 \mathrm{ml}^{-1}$. Aspergillus sp-01 produced maximum (0.53 g.100 ml-1) biomass followed by Aspergillus sp-02 (0.46 g.100 ml $\mathrm{ml}^{-1}$ ) after 1 week of growth (Table 7). The growth of other fungal isolates remained in the range of 0.2 to $0.43 \mathrm{~g} \cdot 100 \mathrm{ml}^{-1}$ as compared with Aspergillus isolates. The $\mathrm{pH}$ of the liquid medium was recorded in the acidic range for all the tested fungal isolates (Table 7).

\section{Production of indole acetic acid and biomass}

The production of indole acetic acid was estimated in the presence of a fixed concentration of tryptophan $\left(500 \mu \mathrm{g} \cdot \mathrm{ml}^{-1}\right)$ in liquid media. Aspergillus sp-05 produced the maximum amount $\left(31.80 \mu \mathrm{g} \cdot \mathrm{ml}^{-1}\right)$ of IAA among the isolates of Aspergillus genera after 1 week of growth (Table 8). The isolates of other fungal genera also produced a significant amount of

Table 7 Quantification of phosphate solubilization by selected fungi

\begin{tabular}{llll}
\hline Isolates & Phosphate $\left(\boldsymbol{\mu g} \cdot \mathbf{m l}^{-\mathbf{1}}\right)$ & Dry biomass $\left(\mathbf{g} \cdot \mathbf{1 0 0} \mathbf{~ m l}^{-\mathbf{1}}\right)$ & $\mathbf{p H}$ \\
\hline Aspergillus sp-01 & $188 \pm 4$ & $0.53 \pm 0.04$ & $5.1 \pm 0.05$ \\
Aspergillus sp-02 & $240 \pm 6$ & $0.46 \pm 0.02$ & $4.5 \pm 0.15$ \\
Aspergillus sp-03 & $258 \pm 5.5$ & $0.44 \pm 0.03$ & $5.5 \pm 0.10$ \\
Aspergillus sp-04 & $230 \pm 5.1$ & $0.28 \pm 0.025$ & $5.6 \pm 0.11$ \\
Aspergillus sp-05 & $245 \pm 2$ & $0.29 \pm 0.023$ & $4.8 \pm 0.20$ \\
Aspergillus sp-06 & $322 \pm 4$ & $0.37 \pm 0.035$ & $4.3 \pm 0.10$ \\
Aspergillus sp-07 & $435 \pm 7.0$ & $0.35 \pm 0.04$ & $5.0 \pm 0.2$ \\
Aspergillus sp-16 & $283 \pm 4.1$ & $0.33 \pm 0.02$ & $5.4 \pm 0.21$ \\
Aspergillus sp-17 & $306 \pm 2.6$ & $0.38 \pm 0.031$ & $5.0 \pm 0.11$ \\
Alternaria sp-01 & $465 \pm 26.1$ & $0.43 \pm 0.030$ & $5.0 \pm 0.20$ \\
Curvularia sp-02 & $295 \pm 24.18$ & $0.21 \pm 0.017$ & $5.7 \pm 0.26$ \\
Fusarium sp-01 & $375 \pm 23.2$ & $0.33 \pm 0.028$ & $5.0 \pm 0.20$ \\
Penicillium sp-03 & $263 \pm 23.51$ & $0.20 \pm 0.018$ & $5.4 \pm 0.21$ \\
Rhizopus sp-02 & $320 \pm 25.3$ & $0.28 \pm 0.023$ & $5.5 \pm 0.31$ \\
\hline
\end{tabular}


Table 8 Quantification of IAA production by selected fungi

\begin{tabular}{|c|c|c|}
\hline Isolates & IAA $\left(\mu \mathrm{g} \cdot \mathrm{ml}^{-1}\right)$ & Dry biomass $\left(\mathrm{g} \cdot 100 \mathrm{ml}^{-1}\right)$ \\
\hline Aspergillus sp-01 & $21.53 \pm 0.25$ & $0.59 \pm 0.04$ \\
\hline Aspergillus sp-02 & $15.40 \pm 0.15$ & $0.51 \pm 0.02$ \\
\hline Aspergillus sp-03 & $26.60 \pm 0.26$ & $0.49 \pm 0.026$ \\
\hline Aspergillus sp-04 & $13.60 \pm 0.1$ & $0.36 \pm 0.025$ \\
\hline Aspergillus sp-05 & $31.80 \pm 0.3$ & $0.30 \pm 0.037$ \\
\hline Aspergillus sp-06 & $19.50 \pm 0.17$ & $0.43 \pm 0.05$ \\
\hline Aspergillus sp-07 & $29.56 \pm 1.24$ & $0.59 \pm 0.05$ \\
\hline Aspergillus sp-10 & $14.40 \pm 0.2$ & $0.25 \pm 0.015$ \\
\hline Aspergillus sp-13 & $24.63 \pm 0.25$ & $0.19 \pm 0.01$ \\
\hline Aspergillus sp-14 & $17.40 \pm 0.26$ & $0.31 \pm 0.03$ \\
\hline Aspergillus sp-15 & $11.50 \pm 0.24$ & $0.23 \pm 0.02$ \\
\hline Aspergillus sp-19 & $22.63 \pm 0.2$ & $0.54 \pm 0.03$ \\
\hline Aspergillus sp-20 & $12.80 \pm 0.41$ & $0.18 \pm 0.022$ \\
\hline Alternaria sp-01 & $24.16 \pm 1.48$ & $0.49 \pm 0.024$ \\
\hline Curvularia sp-02 & $19.17 \pm 1.05$ & $0.37 \pm 0.022$ \\
\hline Fusarium sp-01 & $42.41 \pm 2.82$ & $0.55 \pm 0.041$ \\
\hline Penicillium sp-03 & $37.26 \pm 2.14$ & $0.67 \pm 0.052$ \\
\hline Rhizopus sp-02 & $35.27 \pm 2.02$ & $0.59 \pm 0.046$ \\
\hline
\end{tabular}

\pm indicates SD of three replicates

IAA. Fusarium sp-01 produced a maximum (42.41 $\mu \mathrm{g} \cdot \mathrm{ml}^{-1}$ ) amount of IAA followed by Penicillium sp$03 \quad\left(37.26 \mu \mathrm{g} \cdot \mathrm{ml}^{-1}\right)$, and Rhizopus sp-02 (35.27 $\mu \mathrm{g} \cdot \mathrm{ml}^{-1}$ ) (Table 8).

The fungal isolates exhibited different trends of IAA production. Aspergillus sp-01 and Aspergillus sp-07 isolates produced $0.59 \mathrm{~g} \cdot 100 \mathrm{ml}^{-1}$ biomass after 1 week of the incubation period. The maximum biomass among the isolates of other genera was produced by Penicillium sp-03 (0.67 g.100 ml $\left.\mathrm{m}^{-1}\right)$, whereas Curvularia sp-02 (0.37 g.100 ml-1) produced the minimum biomass (Table 8).

\section{Inoculation effects of selected fungal isolates on wheat growth and yield}

Shoot length Wheat seeds inoculated with plant growth-promoting fungi (Aspergillus niger, Penicillium sp-03, and Rhizopus oryzae) demonstrated a variable plant shoot growth when grown in unfertilized and fertilized clay loam soil. The composite inoculation of microbial cultures resulted in significantly different shoot lengths of wheat at 50, 70, and 145 DAS (Tables 9 and 10). The single inoculation of Aspergillus niger significantly increased the shoot length by $32.8,44.2$, and 86.7 $\mathrm{cm}$ at 50, 70, and 145 DAS, respectively as compared with the uninoculated and unfertilized control. A similar trend was also observed in single inoculations of Penicillium sp-03 and Rhizopus oryzae. Among dual culture inoculations, the combination of Aspergillus niger + Penicillium sp-03 significantly $(P<0.05)$ increased the shoot growth by $35.7,52.2$, and $87.9 \mathrm{~cm}$ at 50,70 , and 145 DAS, respectively as compared with the control. Generally, the shoot length consistently increased in all treatments up to the harvesting stage. The combination of NPK+ Aspergillus niger showed a better response in comparison to NPK+ Penicillium sp03 and NPK+ Rhizopus oryzae inoculants. Triple inoculation treatment (Aspergillus niger + Penicillium sp-03 + Rhizopus oryzae) produced better results than single

Table 9 Effect of fungal inoculation on different parameters of wheat plant parts at 50 and 70 days after sowing

\begin{tabular}{|c|c|c|c|c|c|c|c|c|}
\hline & \multicolumn{2}{|c|}{ Shoot length $(\mathrm{cm})$} & \multicolumn{2}{|c|}{ Shoot weight (g) } & \multicolumn{2}{|c|}{ Shoot weight dry (g) } & \multicolumn{2}{|c|}{ Leaf number } \\
\hline & 50 days & 70 days & 50 days & 70 days & 50 days & 70 days & 50 days & 70 days \\
\hline \multicolumn{9}{|l|}{ Treatments } \\
\hline Control & $14.5^{\mathrm{g}^{*}}$ & $24.9^{h}$ & $12.6^{\mathrm{i}}$ & $20.5^{i}$ & $6.9^{9}$ & $11.4^{\mathrm{g}}$ & $15^{9}$ & $24^{f}$ \\
\hline NPK & $28.5^{\mathrm{bc}}$ & $35.8^{\mathrm{fg}}$ & $16.8^{\mathrm{ef}}$ & $24.8^{\mathrm{gh}}$ & $12.3^{\mathrm{e}}$ & $16.4^{\mathrm{e}}$ & $22^{d}$ & $26^{\mathrm{ef}}$ \\
\hline NPK + Aspergillus niger (Asp-07) & $40.6^{\mathrm{ab}}$ & $56.4^{b}$ & $24.3^{b}$ & $38.9^{\mathrm{b}}$ & $24.8^{\mathrm{b}}$ & $24.7^{\mathrm{b}}$ & $27^{\mathrm{b}}$ & $36^{\mathrm{bc}}$ \\
\hline NPK + Penicillium sp-03 & $35.2^{\text {cd }}$ & $49.5^{c}$ & $20.5^{c}$ & $34.5^{\mathrm{cd}}$ & $18.6^{c}$ & $20.3^{c}$ & $24^{c}$ & $31^{d}$ \\
\hline NPK + Rhizopus oryzae (Rzp-02) & $31.4^{\text {de }}$ & $45.6^{d}$ & $18.1^{\mathrm{de}}$ & $30.6^{\mathrm{e}}$ & $15.9^{d}$ & $17.9^{\mathrm{d}}$ & $20^{\mathrm{e}}$ & $28^{\mathrm{e}}$ \\
\hline Aspergillus niger & $32.8^{d}$ & $44.2^{d}$ & $16.4^{\mathrm{fg}}$ & $30.8^{\mathrm{e}}$ & $14.8^{\mathrm{d}}$ & $16.5^{\mathrm{de}}$ & $24^{c}$ & $32^{d}$ \\
\hline Penicillium sp-03 & $25.6^{\mathrm{ef}}$ & $38.1^{\text {ef }}$ & $15.1^{\mathrm{gh}}$ & $26.2^{\mathrm{fg}}$ & $11.7^{\mathrm{e}}$ & $14.9^{f}$ & $20^{e}$ & $27^{e}$ \\
\hline Rhizopus oryzae & $20.3^{\mathrm{fg}}$ & $33.7^{9}$ & $13.9^{\mathrm{hi}}$ & $23.1^{\text {h }}$ & $8.5^{f}$ & $11.6^{\mathrm{g}}$ & $17^{f}$ & $25^{f}$ \\
\hline Aspergillus niger + Penicillium sp-03 & $35.7^{\mathrm{b}}$ & $52.2^{c}$ & $21.5^{c}$ & $35.5^{c}$ & $18.7^{c}$ & $21.5^{c}$ & $27^{\mathrm{b}}$ & $38^{\mathrm{b}}$ \\
\hline Aspergillus niger + Rhizopus oryzae & $25.3^{c}$ & $45.6^{d}$ & $18.4^{d}$ & $32.3^{d}$ & $15.7^{d}$ & $17.4^{d}$ & $25^{\mathrm{c}}$ & $35^{c}$ \\
\hline Penicillium sp-03 + Rhizopus oryzae & $22.6^{\mathrm{e}}$ & $39.8^{\mathrm{e}}$ & $15.1^{\mathrm{g}}$ & $27.4^{f}$ & $12.8^{\mathrm{e}}$ & $13.9^{f}$ & $22^{\mathrm{d}}$ & $28^{\mathrm{e}}$ \\
\hline Aspergillus niger + Penicillium sp-03 + Rhizopus oryzae & $43.5^{\mathrm{a}}$ & $60.9^{\mathrm{a}}$ & $27.8^{\mathrm{a}}$ & $43.5^{\mathrm{a}}$ & $27.3^{\mathrm{a}}$ & $29.4^{\mathrm{a}}$ & $29^{a}$ & $41^{\mathrm{a}}$ \\
\hline LSD at $5 \%$ & 1.35 & 3.43 & 1.46 & 2.93 & 1.29 & 1.45 & 1.78 & 2.40 \\
\hline
\end{tabular}

* Means in columns followed by different superscript letters are significantly different at $P<0.05$ as determined by Duncan's multiple range test 
Table 10 Effect of fungal inoculation on the yield attributes of wheat

\begin{tabular}{|c|c|c|c|c|c|c|c|c|c|c|}
\hline & $\begin{array}{l}\text { Shoot } \\
\text { weight } \\
\text { Fresh }(\mathrm{g})\end{array}$ & $\begin{array}{l}\text { Shoot } \\
\text { weight Dry } \\
\text { (g) }\end{array}$ & $\begin{array}{l}\text { Shoot } \\
\text { length } \\
\text { (cm) }\end{array}$ & $\begin{array}{l}\text { Leaf } \\
\text { no. }\end{array}$ & $\begin{array}{l}\text { Spikelet } \\
\text { number/ } \\
\text { Ear }\end{array}$ & $\begin{array}{l}\text { Ear } \\
\text { number }\end{array}$ & $\begin{array}{l}\text { Grain } \\
\text { no./ } \\
\text { Ear } \\
\end{array}$ & $\begin{array}{l}1000 \text { seeds } \\
\text { weight }(g)\end{array}$ & $\begin{array}{l}\text { Grain } \\
\text { yield/ } \\
\text { plant }\end{array}$ & $\begin{array}{l}\text { Protein } \\
\text { content } \\
(\%)\end{array}$ \\
\hline \multicolumn{11}{|l|}{ Treatments } \\
\hline Control & $12.9^{h^{*}}$ & $5.2^{9}$ & $71.9^{e}$ & $27^{f}$ & $49^{e}$ & $4^{c}$ & $32^{9}$ & $33.5^{f}$ & $7.8^{\mathrm{j}}$ & $10.8^{\mathrm{g}}$ \\
\hline NPK & $26.4^{\mathrm{cd}}$ & $8.9^{b}$ & $86.8^{\mathrm{b}}$ & $34^{d}$ & $67^{c}$ & $6^{a}$ & $53^{\mathrm{cd}}$ & $53.5^{\mathrm{b}}$ & $12.8^{\text {de }}$ & $15.5^{\mathrm{bc}}$ \\
\hline NPK + Aspergillus niger & $30.2^{b}$ & $9.4^{\mathrm{b}}$ & $92.2^{\mathrm{ab}}$ & $38^{\mathrm{b}}$ & $74^{\mathrm{ab}}$ & $6^{\mathrm{a}}$ & $59^{b}$ & $60.3^{\mathrm{a}}$ & $17.4^{\mathrm{b}}$ & $16.8^{\mathrm{ab}}$ \\
\hline NPK + Penicillium sp-03. & $25.5^{\mathrm{de}}$ & $8.3^{\mathrm{cd}}$ & $85.8^{\mathrm{bc}}$ & $35^{c d}$ & $68^{c}$ & $6^{\mathrm{a}}$ & $51^{\text {de }}$ & $54.6^{b}$ & $13.1^{d}$ & $14.6^{\mathrm{cd}}$ \\
\hline NPK + Rhizopus oryzae & $20.2^{f}$ & $7.6^{e}$ & $82.5^{c d}$ & $34^{d}$ & $63^{d}$ & $6^{a}$ & $48^{\mathrm{ef}}$ & $51.3^{b c}$ & $10.7^{g h}$ & $13.9^{\text {de }}$ \\
\hline Aspergillus niger & $24.1^{e}$ & $8.0^{\mathrm{d}}$ & $86.7^{\mathrm{b}}$ & $35^{c}$ & $65^{c}$ & $5^{b}$ & $52^{d}$ & $52.6^{\mathrm{b}}$ & $12.6^{\mathrm{ef}}$ & $14.1^{d}$ \\
\hline Penicillium sp-03. & $19.5^{f}$ & $6.9^{f}$ & $78.3^{\text {de }}$ & $33^{\mathrm{de}}$ & $61^{d}$ & $5^{\mathrm{b}}$ & $47^{f}$ & $47.8^{\mathrm{cd}}$ & $10.2^{\mathrm{h}}$ & $12.7^{\mathrm{ef}}$ \\
\hline Rhizopus oryzae & $15.8^{9}$ & $5.8^{\mathrm{g}}$ & $73.3^{e}$ & $32^{\mathrm{e}}$ & $59^{d}$ & $6^{\mathrm{a}}$ & $46^{f}$ & $41.6^{\mathrm{e}}$ & $8.9^{\mathrm{i}}$ & $11.6^{\mathrm{fg}}$ \\
\hline $\begin{array}{l}\text { Aspergillus niger + } \\
\text { Penicillium sp-03. }\end{array}$ & $28.2^{c}$ & $8.8^{\mathrm{bc}}$ & $87.9^{b}$ & $37^{\mathrm{bc}}$ & $69^{\mathrm{bc}}$ & $6^{a}$ & $56^{\mathrm{bc}}$ & $54.9^{b}$ & $15.3^{c}$ & $15.9^{b}$ \\
\hline $\begin{array}{l}\text { Aspergillus niger + Rhizopus } \\
\text { oryzae }\end{array}$ & $24.3^{e}$ & $7.7^{\mathrm{de}}$ & $82.6^{c}$ & $34^{d}$ & $64^{\mathrm{cd}}$ & $5^{b}$ & $52^{d}$ & $51.6^{\mathrm{b}}$ & $13.8^{d}$ & $14.9^{c}$ \\
\hline $\begin{array}{l}\text { Penicillium sp-03 + Rhizo- } \\
\text { pus oryzae }\end{array}$ & $19.5^{f}$ & $7.1^{\text {ef }}$ & $78.9^{d}$ & $34^{d}$ & $62^{d}$ & $4^{c}$ & $49^{e}$ & $46.5^{d}$ & $11.6^{\mathrm{fg}}$ & $12.7^{e}$ \\
\hline $\begin{array}{l}\text { Aspergillus niger }+ \\
\text { Penicillium sp- } 03+\text { Rhizo- } \\
\text { pus oryzae }\end{array}$ & $34.2^{\mathrm{a}}$ & $10.7^{\mathrm{a}}$ & $97.5^{\mathrm{a}}$ & $42^{\mathrm{e}}$ & $79^{\mathrm{a}}$ & $6^{a}$ & $66^{a}$ & $64.3^{\mathrm{a}}$ & $19.7^{\mathrm{a}}$ & $17.9^{\mathrm{a}}$ \\
\hline LSD at $5 \%$ & 1.90 & 0.626 & 6.49 & 2.67 & 5.05 & 0.424 & 3.98 & 4.00 & 1.03 & 1.35 \\
\hline
\end{tabular}

* Means in columns followed by different superscript letters are significantly different at $P<0.05$ as determined by Duncan's multiple range test

and dual inoculation treatments. The composite application of Aspergillus niger + Penicillium sp-03 + Rhizopus oryzae significantly $(P<0.05)$ enhanced the shoot length by $43.5,60.9$, and $97.5 \mathrm{~cm}$ during all three stages of plant growth.

Fresh shoot biomass The fresh shoot mass of plants uprooted at 60, 90, and 145 DAS varied significantly (Tables 9 and 10). Aspergillus niger significantly $(P<$ 0.05 ) increased the fresh shoot biomass by $50.24 \%$ at 70 DAS as compared with unfertilized treatment. Generally, the single and dual cultures of plant growth-promoting fungi demonstrated better performance than the control. The combination of Aspergillus niger + Penicillium sp03 was found to be superior among dual inoculation treatments and significantly $(P<0.05)$ increased the fresh mass of shoots at 70 DAS. The combination of $\mathrm{NPK}+$ Aspergillus niger enhanced the shoot weight by 24.3, 38.9, and $30.2 \mathrm{~g}$ at 50,70, and 145 DAS, respectively, in comparison to NPK + Penicillium sp-03 and NPK + Rhizopus oryzae inoculants. The tripartite combination of fungi Aspergillus niger + Penicillium sp-03 + Rhizopus oryzae exhibited a more profound effect as compared with single, dual, and other inoculation treatments. The consortium of three inoculant cultures significantly $(P<0.05)$ increased the fresh shoot biomass by $27.8,43.5$, and $34.2 \mathrm{~g}$ at 50,70 , and 145 DAS respectively, as compared with the controls.
Dry shoot biomass The dry matter accumulation in the top parts of the wheat crop differed among treatments at 50, 70, and 145 DAS (Tables 9 and 10). The coinoculation of Aspergillus niger + Penicillium sp-03 + Rhizopus oryzae remained superior to all other treatments and significantly enhanced the shoot dry biomass by $27.3,29.4$, and $10.7 \mathrm{~g}$ at 50,70 , and 145 DAS, respectively relative to the control. In comparison, the dual inoculation treatment (Aspergillus niger + Penicillium sp03) significantly $(P<0.05)$ increased the dry matter accumulation in shoots by $18.7,21.5$, and $8.8 \mathrm{~g}$ at the three stages (50, 70, and $145 \mathrm{DAS}$ ) of plant growth, respectively as compared with the control. In general, this dual combination performed better than other dual inoculation treatments. The dual inoculation of NPK with $A s$ pergillus niger significantly increased the shoot biomass by $24.8,24.7$, and $9.4 \mathrm{~g}$ at 50,70 , and 145 DAS as compared with NPK + Penicillium sp-03 and NPK + Rhizopus oryzae inoculations. The single inoculation treatments of Aspergillus niger also significantly increased the shoot dry biomass by $14.8,16.5$, and $8.0 \mathrm{~g}$ as compared with the unfertilized control treatment at 50 , 70 , and 145 DAS respectively.

Leaf number Generally, the single inoculation treatments of Aspergillus niger, Penicillium sp-03, and Rhizopus oryzae significantly $(P<0.05)$ increased the leaf number by $29.62 \%, 22.22 \%, 18.51 \%$, respectively than 
controls at 145 DAS in 2007. The combination of NPK + Aspergillus niger significantly $(P<0.05)$ increased the leaf number by $80 \%, 50 \%, 40.74 \% /$ Ear at 50,70 , and 145 DAS, respectively than the control treatment (Tables 9 and 10). The results indicated that the inoculation of Aspergillus niger in combination with plant growth-promoting Penicillium sp-03 significantly $(P<0.05)$ increased the leaf number by $58.33 \%$ and $37.03 \%$ at 70 and 145 DAS, respectively as compared with the inoculation with unfertilized treatment or control. The combination of three cultures (Aspergillus niger + Penicillium sp-03 + Rhizopus oryzae) produced better results than dual and single inoculation treatments (Aspergillus niger + Penicillium sp-03, NPK + Aspergillus niger, Aspergillus niger, and Penicillium sp-03) and significantly $(P<0.05)$ increased the leaf numbers of wheat plants (Tables 9 and 10).

Spikelet number The results presented in Table 10 indicate that the inoculation with a combination of Aspergillus niger and plant growth-promoting Penicillium sp03 significantly $(P<0.05)$ increased the spikelet numbers as compared with the inoculation with unfertilized treatment or control. Generally, the combination of three cultures (Aspergillus niger + Penicillium sp-03 + Rhizopus oryzae) produced better results than dual and single inoculation treatments (Aspergillus niger + Penicillium sp-03, NPK + Aspergillus niger, Aspergillus niger, and Penicillium sp-03) and significantly $(P<0.05)$ increased the spikelet numbers of wheat plants. The combination of NPK + Aspergillus niger significantly $(P<0.05)$ increased the number of spikelets by $51.02 \% /$ Ear at harvesting time as compared with all other treatments. The single inoculation treatment of Aspergillus niger, Penicillium sp-03, and Rhizopus oryzae also significantly $(P<$ 0.05 ) increased the spikelet numbers by $32.65 \%, 24.48 \%$, and $20.40 \%$, respectively in comparison with the control.

Ear number The treatments of NPK and Aspergillus niger, Penicillium sp-03 and Rhizopus oryzae, Penicillium sp-03 + Rhizopus oryzae, and Aspergillus niger + Penicillium sp-03 + Rhizopus oryzae depicted a significant $(P<$ $0.05) 50 \%$ increase as compared with the unfertilized and uninoculated control. The combination of Penicillium sp-03 + Rhizopus oryzae also showed a similar effect on the ear numbers of the wheat plant. A single inoculation of Penicillium sp-03 and Rhizopus oryzae significantly $(P<0.05)$ increased the ear numbers $(25 \%)$ than control (Table 10).

Grain number The results presented in Table 10 indicate that inoculation of Aspergillus niger in combination with plant growth-promoting Penicillium sp-03 significantly $(P<0.05)$ increased the grain number by $75 \% /$ Ear as compared with inoculation with unfertilized treatment or control. The combination of three cultures (Aspergillus niger + Penicillium sp-03 + Rhizopus oryzae) proved significantly $(P<0.05)$ better than dual and single inoculation treatments (Aspergillus niger + Penicillium sp-03, NPK + Aspergillus niger, Aspergillus niger, and Penicillium sp-03) and increased the grain numbers by $106 \% /$ Ear of the wheat plants. The combination of NPK + Aspergillus niger increased the number of grains by $84.37 \% /$ Ear at harvesting time as compared with the control. The single inoculation treatment of Aspergillus niger, Penicillium sp-03, and Rhizopus oryzae also significantly $(P<0.05)$ increased the number of the grains by $62.5 \%, 46.87 \%$, and $43.75 \% /$ Ear, respectively, in comparison to the control (Table 10).

Seed yield The seed yield was expressed in terms of both weight of 1000 seeds $(\mathrm{g})$ and seed weight $\left(\mathrm{g} \cdot \mathrm{plant}^{-1}\right)$ after single and combined applications of beneficial rhizosphere microorganisms, as presented in Table 10 . All treatments significantly increased the grain production during the wheat crop experiments. Single inoculation with Aspergillus niger significantly $(P<0.05)$ increased the grain yield (weight of 1000 seeds) by $57.01 \%$ as compared with the control. The dual inoculation treatments comparatively performed better than the single inoculation, fertilizer treatment, and control. However, inoculation with Aspergillus niger + Penicillium sp-03 was found to be the most effective than other single and dual inoculation treatments. The highest grain yield of 64.3 g.1000 seeds ${ }^{-1}$ was obtained in Aspergillus niger + Penicillium $\mathrm{sp}-03+$ Rhizopus oryzae treatment, which was even greater than the best performing combination of NPK + Aspergillus niger (Table 10).

The single inoculation of Aspergillus niger significantly $(P<0.05)$ increased the seed yield by $61.53 \%$ than control. The co-inoculation of Aspergillus niger + Penicillium sp-03 was found better than other dual culture treatments. Triple inoculation of Aspergillus niger + Penicillium sp-03 + Rhizopus oryzae enhanced the seed yield by $19.7 \mathrm{~g}$.plant ${ }^{-1}$ as compared with the control. The triple inoculation factor had a significantly greater effect on seed yield as compared with dual culture treatments. The application of NPK + Aspergillus niger was noted to be significantly superior to other combined treatments of fertilizers and cultures and increased the seed yield by 17.4 g.plant ${ }^{-1}$ as compared with the control (7.80 g.plant $\left.{ }^{-1}\right)$.

Seed protein The effect of microbial inoculation on seed protein (SP) was variable (Table 10). The maximum average seed protein $(17.9 \%)$ was observed with the inoculation of Aspergillus niger + Penicillium sp-03 + Rhizopus oryzae in 2007. Among the dual inoculation 
treatments, the combination of Aspergillus niger + Penicillium sp-03 significantly enhanced the SP (5.10\%) as compared with the control. The single inoculation of Aspergillus niger produced $14.1 \%$ SP as compared with the uninoculated and unfertilized control $(10.80 \%)$. The application of NPK + Aspergillus niger was significantly superior to other combined treatments with fertilizers and demonstrated $16.8 \%$ seed protein as compared with $10.80 \%$ in the control. The comparison of SP mean values revealed that it decreased in the following order: triple $<$ dual $<$ single inoculation.

\section{Discussion}

Resident soil fungi and bacteria are crucial for maintaining soil fertility and crop productivity. The role of plant growth-promoting rhizobacteria and mycorrhizal fungi is well known. However, the rich diversity of free-living rhizospheric fungi has not been systematically screened and evaluated as plant growth-promoting fungi (PGPF). Since the majority of free-living soil fungi is not hostspecific; therefore, promising isolates can be developed as broad host range bio-inoculants for crops. During this study, common free-living soil fungi were isolated and evaluated as potential PGPF bio-inoculants. The screening was carried out in vitro and soil-plant system.

The extracellular enzymes of fungal origin have various industrial and biotechnological applications in food processing, manufacturing of detergents, textiles, pharmaceutical products, medical therapy, and molecular biology (Wösten 2019). Different extracellular fungal enzymes are known to degrade complex carbonaceous and nitrogenous substances of soil to synthesize humus that enhances soil fertility and nutrient availability for other organisms including plants (Frąc et al. 2018). These enzymes have been comprehensively studied and utilized in industrial applications. The fungal extracellular enzymes can effectively degrade organic matter and facilitate nutrient recycling. The isolates with efficient enzyme production can better survive in the rhizosphere and may also be indirectly beneficial for plant growth through nutrient turnover. Therefore, fungal extracellular enzymes with potential PGP traits were evaluated.

Lipase activity was noted to be the highest (95.52\%) followed by amylase (61.11\%), cellulase (41.79\%), and chitinase $(35.82 \%)$ among extracellular enzymes isolated from fungal strains. The production of these enzymes varied among different genera and even among the isolates of the same genus such as Aspergillus, Curvularia, and Mycelia Sterillia group. The differences in the genetic makeup, nature and regulatory mechanisms involved in enzyme synthesis might be the reasons behind varying enzyme production (Crueger et al. 1990). Lipases act upon the organic substrates in the rhizosphere to release the minerals, which are available for other microorganisms and plants (Costa and Peralta 1999; Wadia and Jain 2017). Amylase activity was next to lipase in most of the genera except for some isolates such as Fusarium, Chlamydospora, Mucor, Rhizopus, and Verticillium. The production of amylases is widely distributed among filamentous fungi (Rekha et al. 2013; Ogbonna et al. 2014; Verma and Verma 2018). Such fungi solubilize and utilize starch to co-mineralize nitrogenous compounds for better availability to plants in the rhizosphere. Similarly, cellulolytic activities were observed among certain groups of fungi like Aspergillus, Curvularia, Fusarium, Monotospora, Tricophyton, Trichoderma, Mycelia sterillia, Monillia, and some other isolates belonging to unidentified fungal strains. Fungi with cellulolytic activity play an important role in the enrichment and acceleration of the composting process leading to increased mineralization in the rhizosphere and might also modulate the microbial activity in the rhizosphere (Ram et al. 2014; Reddy et al. 2014; Saxena et al. 2015). Chitin is one of the most important structural polysaccharides that provide mechanical strength to organisms. Chitin is synthesized by plants, animals, and certain microbes except for bacteria and actinomycetes. Chitin-degrading activity is predominant among soil actinomycetes, bacteria, and fungi (Nampally et al. 2015; Veliz et al. 2017). The chitinase production might also have a lytic effect on phytopathogens containing chitin in their cell wall constituents. However, the actual mechanisms of phytopathogen suppression by a biocontrol organism through chitinase production have not been well illustrated. It was hypothesized during a study that chitinase may directly break down the fungal cell walls (Veliz et al. 2017). However, the role of chitinases in the carbon cycle of the biosphere is well known (Rathore and Gupta 2015).

Among the tested fungi, 37.31\% fungal isolates belonging to Aspergillus, Curvularia, Alternaria, Trichophyton, Hormodendrum, Monotospora, Mucor, Microsporum, Penicillium, Trichoderma, and Verticillium solubilized phosphate. Several unidentified isolates (15) also served as phosphate solubilizers. The production of organic acid was detected among $28.35 \%$ fungal isolates belonging to different genera such as Aspergillus. Alternaria, Penicillium, Mucor, Fusarium, Trichoderma, Verticillium, and many unidentified isolates. Our findings of phosphate solubilization by Aspergillus, Curvularia, Alternaria, Trichophyton, Hormodendrum, Monotospora, Mucor, Microsporum, Penicillium, Trichoderma, and Verticillium are in agreement with previous studies (Gaur 1990, Scervino et al. 2010; Altaf et al. 2018; Elias et al. 2016). The phosphate-solubilizing capacity of Trichophyton, Hormodendrum, Monotospora, and Microsporum species from Northern Indian soil is probably 
the first report. Similarly, our findings of organic acid production by certain fungi (Aspergillus, Rhizopus, Alternaria, Penicillium, Monotospora, and Verticillium) are in line with previous reports (Scervino et al. 2010; Liaud et al. 2014). The production of plant growth regulators is considered an important PGP trait of plant-associated microbes. The rhizospheric fungi capable of producing plant growth hormones (indole acetic acid (IAA)) might directly influence plant growth promotion (Chanclud and Morel 2016; Altaf et al. 2018). Forty-four (65.67\%) isolates out of a total 67 produced detectable amounts of IAA and IAA-like compounds in vitro in the presence of tryptophan. These findings are supported by the previous reports on IAA production by Aspergillus, Curvularia, Alternaria, Trichophyton, and Penicillium (Abri et al. 2015; Fu et al. 2015; Altaf et al. 2018; Shah et al. 2019). Siderophore production is considered an indirect mechanism of plant growth promotion by rhizospheric microorganisms (Altaf et al. 2018). To solubilize ferric iron, many microbes utilize an efficient system consisting of low molecular weight ( $\geq 1000 \mathrm{da}$ ) compounds with high iron affinity, known as siderophores. Siderophores have recently received much attention in agriculture as a mechanism of promoting plant health and protection of plants from other fungal pathogens by depriving them of iron (Altaf et al. 2018; Kumar et al. 2018). Organic acid produced by Aspergillus spp. (citric acid and oxalic acid) might serve as siderophores (Haas 2014). Aspergillus spp. is known to produce hydroxamate-like siderophores (Haas 2014; Patel et al. 2017). During this study, siderophore production was noted in eight Aspergillus isolates followed by the isolates of Curvularia, Alternaria, Monotospora, Penicillium, Trichoderma, Chlamydospora, Mucor, and Trichothecium. Certain isolates of Mycelia sterilia and unidentified fungi could also produce siderophores. However, such activity was not detected among Rhizopus, Trichophyton, and Verticillium. Hydroxamate-type siderophore production in fungi belonging to zygomycetes, basidiomycetes, and ascomycetes has been reported, whereas the members of Mucorales produced carboxylates (Comensoli et al. 2017). Similarly, the production of ammonia by $91.04 \%$ fungi demonstrated their role in ammonification, which is the key compound for further cycling of nitrogen elements (Espenberg et al. 2018). The role of ammonia production in plant growth promotion is well known. The production of antibiotics by eight isolates of test fungi inhibited or suppressed pathogenic bacteria. However, such activity should be thoroughly investigated as it can also inhibit useful bacteria (Rani and Jain 2017). The antibiotic production by tested fungi signifies their ecological role for better survival and occupation of ecological niche in the rhizosphere.
The rhizospheric soil is rich in fungal diversity; therefore, inoculant strain must be a competitive and effective rhizosphere colonizer. These fungi have a high level of metal tolerance (data not shown) and are expected to have competitive advantages for survival and effective colonization in the rhizosphere. The consortium used in this study was based on the compatibility of the isolates and expressed multiple biochemical and PGP traits. The three most promising fungal isolates were selected and used as inoculants in single and combined treatments to assess their inoculation effect on the growth and yield of wheat under field conditions.

Inoculation response of single-tested fungi and in combinations of two or three species showed stimulatory effect on plant growth and yield attributes of wheat crop like shoot length as well as weight, spikelet, ear and grain number, seed yield, and protein content. Generally, the inoculation of three cultures (Aspergillus niger + Penicillium sp-03 + Rhizopus oryzae) together was observed most effective as compared with dual and single inoculation treatments and showed a significant increase in yield attributes of the wheat plants. Triple inoculation of Aspergillus niger + Penicillium sp-03 + Rhizopus oryzae enhanced the seed as compared with control. This triple inoculation factor had significantly greater effect on seed yield as compared with dual culture treatments. The combined effects of PFPG inoculation is expected due to the probability of expression of desired plant growth-promoting traits of these fungi which might have influenced the plant growth both by direct and indirect mechanisms. Inoculation of Aspergillus niger combination with plant growth-promoting Penicillium sp-03 significantly increased the grain number $75 \% / E a r$ as compared with the inoculation with unfertilized treatment or control. The phosphate-solubilizing capabilities of filamentous fungi and bacteria have been studied. Wahid and Mehana (2000) have reported the consortium effect of three phosphate-solubilizing fungal isolates (Aspergillus niger, A. fumigatus, and Penicillium pinophilum) on the faba bean and wheat. They observed that the yield of wheat and faba bean plants increased in response to the soil inoculation with three fungal species, and Penicillium pinophilum played the most effective role. The yield of wheat grains increased by 28.9 and $32.8 \%$ in the soil treated with rock phosphate and superphosphate, respectively. Similarly, the same treatments increased the production of faba bean seeds by 14.7 and $29.4 \%$. The phosphorus uptake of both crops significantly increased after the inoculation of soil with tested fungi.

The bacterial isolate Pseudomonas sp. BR2, a mycorrhiza helper bacterium, significantly enhanced the early emergence of wheat seedlings (5 days after planting) under field conditions and increased the root dry matter 
yield by $128 \%$. The two TPR-solubilizing fungal isolates Aspergillus awamori Nakazawa $\mathrm{C} 1$ and Penicillium chrysogenum Thom $\mathrm{C} 13$ also increased the root dry matter yields by 60 and 44\%, respectively (Babana and Antoun 2006). Wakelin et al. (2007) tested three phosphatesolubilizing fungi (Penicillium radicum, Penicillium bilalae, and Penicillium sp. KC6-W2) to assess their ability in increasing the growth and phosphorus $(\mathrm{P})$ nutrition of wheat, medic, and lentil. Penicillium sp. KC6-W2 was found to be the best plant growth-promoting (PGP) strain and significantly increased the shoot growth and dry mass in seven of the nine experiments.

The effect of three phosphate-solubilizing fungi including Penicillium expansum, Mucor ramosissimus, and Candida krissii on the seedling growth of wheat, has been reported by Xiao et al. (2009). All the isolates promoted growth, availability of soil phosphorus, and nitrogen uptake of wheat seedlings in the soil containing rock phosphate under pot cultivation conditions. In recent years, researchers are focusing on indigenous soil fungi as PGPF. For instance, Hossain et al. (2014) have demonstrated the ability of soil Penicillium sp. G15-1 in promoting plant growth and providing protection against plant pests and pathogens in cucumber plants. Recently, the plant growth-promoting activities of Alternaria sp. A13 have been reported in the Chinese herbal plant Salvia miltiorrhizae through promoting root growth and accumulation of active ingredients (Zhou et al. 2018).

\section{Conclusion}

Based on the extensive screening and evaluations, this study concludes that free-living soil fungi have great potential in promoting plant growth through diverse metabolic activities. These fungi require further detailed investigations to develop bio-inoculants with broadspectrum fitness to wheat and other crops under normal and stress conditions.

\section{Acknowledgement}

The author, IM, is thankful to University Grant Commission, New Delhi for providing Non-NET fellowship during the study at the Aligarh Muslim University, Aligarh.

\section{Authors' contributions}

IM conducted the experiments. HA prepared the early draft and edited the final draft of the manuscript. MM participated in data analysis. KE participated in data analysis. S participated in the language editing of the manuscript. IA designed the experiments and wrote up the manuscript. The author(s) read and approved the manuscript.

\section{Funding}

None.

\section{Availability of data and materials}

The data sets used and/or analyzed during the current study are available from the corresponding author on a reasonable request.

\section{Declarations}

Ethics approval and consent to participate

Not applicable.

Consent for publication

Not applicable.

\section{Competing interests}

The authors declare that they have no known competing interests that could have appeared to influence the work reported in this paper.

\section{Author details}

'Department of Agricultural Microbiology, Faculty of Agricultural Sciences, Aligarh Muslim University, Aligarh 202002, India. ${ }^{2}$ Present Address: Nazz Apartment, Kalyanpur West Ring road, Lucknow, UP, India. ${ }^{3}$ Department of Biology, Faculty of Applied Science, Umm Al-Qura University, Makkah, Saudi Arabia. ${ }^{4}$ Research Laboratories Unit, Faculty of Applied Science, Umm Al-Qura University, Makkah, Saudi Arabia. ${ }^{5}$ Department of Agricultural Microbiology, Faculty of Agriculture, Fayoum University, Fayoum, Egypt.

Received: 17 May 2021 Accepted: 19 July 2021

Published online: 29 July 2021

\section{References}

Abri TK, Sengin EL, Sjahrir R (2015) Production of indole acetic acid (IAA) hormone from fungal isolates collected from rhizosphere of aromatic rice in Tana Toraja. Int J Curr Res Biosc Plant Biol 2:198-201

Ahmad F, Ahmad I, Aqil F, Wani A, Sousche YS (2006) Plant growth promoting potential of free-living diazotrophs and other rhizobacteria isolated from Northern Indian soil. Biotechnol J 1(10):1112-1123. https://doi.org/10.1002/ biot.200600132

Ahmad I, Beg AZ (2001) Antimicrobial and phytochemical studies on 45 Indian medicinal plants against multi-drug resistant human pathogens. J Ethnopharmacol 74(2):113-123. https://doi.org/10.1016/s0378-8741(00)00335-4 Altaf MM, Imran M, Abulreesh HH, Khan MS, Ahmad I (2018) Diversity and applications of Penicillium spp. in plant-growth promotion. In: Gupta VK, Rodriguez-Couto S (eds) New and Future Developments in Microbial Biotechnology and Bioengineering: Penicillium System, Prosperities and Applications. Elsevier B.V., Amsterdam, pp 261-276. https://doi.org/10.1016/ B978-0-444-63501-3.00015-6

Babana AH, Antoun H (2006) Effect of Tilemsi phosphate rock-solubilizing microorganisms on phosphorus uptake and yield of field-grown wheat (Triticum aestivum L.) in Mali. Plant Soil 287:51-58. https://doi.org/10.1007/ s11104-006-9060-0

Bhardwaj D, Ansari MW, Sahoo RK, Tuteja N (2014) Biofertilizers function as key player in sustainable agriculture by improving soil fertility, plant tolerance and crop productivity. Microb Cell Fact 13:1-10. https://doi.org/10.1186/14 75-2859-13-66

Bona E, Cantamessa S, Massa N, Manassero P, Marsano F, Copetta A, Berta G (2017) Arbuscular mycorrhizal fungi and plant growth-promoting pseudomonads improve yield, quality and nutritional value of tomato: a field study. Mycorrhiza 27(1):1-11. https://doi.org/10.1007/s00572-016-0727-y

Campbell LL, Williams OB (1951) A study of chitin-decomposing micro-organisms of marine origin. Microbiol. 5:894-905

Cappuccino JG, Welsh CT (2018) Microbiology, a laboratory manual, 11th edn. Pearson Education Ltd, Essex

Carrara JE, Walter CA, Hawkins JS, Peterjohn WT, Averill C, Brzostek ER (2018) Interactions among plants, bacteria, and fungi reduce extracellular enzyme activities under long-term N fertilization. Glob Chang Biol 24(6):2721-2734. https://doi.org/10.1111/gcb.14081

Chanclud E, Morel JB (2016) Plant hormones: a fungal point of view. Mol Plant Pathol 17(8):1289-1297. https://doi.org/10.1111/mpp.12393

Comensoli L, Bindschedler S, Junier P, Joseph E (2017) Iron and fungal physiology: a review of biotechnological opportunities. Adv Appl Microbiol 98:31-60. https://doi.org/10.1016/bs.aambs.2016.11.001

Costa MAF, Peralta RM (1999) Production of lipase by soil fungi and partial characterization of lipase from a selected strain (Penicillium wortmanii). J Basic Microbiol 39(1):11-15. https://doi.org/10.1002/(SICI)1521-4028(199903)39:1< 11::AID-JOBM11>3.0.CO;2-8 
Crueger W, Crueger A, Brock TD (1990) Biotechnology: a textbook of industrial microbiology. Sinauer Associates, Sunderland

Elias F, Woyessa D, Muleta D (2016) Phosphate solubilization potential of rhizosphere fungi isolated from plants in Jimma Zone, Southwest Ethiopia. Int J Microbiol 2016:Article ID 5472601. https://doi.org/10.1155/2016/5472601

El-Morsy EM, Hassan HM, Ahmed E (2017) Biodegradative activities of fungal isolates from plastic contaminated soils. Mycosphere 8(8):1071-1087. https:// doi.org/10.5943/mycosphere/8/8/13

Espenberg M, Truu M, Mander Ü, Kasak K, Nõlvak H, Ligi T, Truu J (2018) Differences in microbial community structure and nitrogen cycling in natural and drained tropical peatland soils. Sci Rep 8:4742. https://doi.org/10.1038/ s41598-018-23032-y

Frąc M, Hannula SE, Bełka M, Jędryczka M (2018) Fungal biodiversity and their role in soil health. Front Microbiol 9:707. https://doi.org/10.3389/fmicb.2018. 00707

Fu SF, Wei JY, Chen HW, Liu YY, Lu HY, Chou JY (2015) Indole-3-acetic acid: a widespread physiological code in interactions of fungi with other organisms. Plant Signal Behav 10(8):e1048052. https://doi.org/10.1080/15592324.2015.104 8052

Gaur AC (1990) Phosphate solubilizing micro-organisms as biofertilizer. Omega scientific publishers, Delhi

Gilman JC (2001) A manual of soil fungi, 2nd edn. Biotech Book Pvt. Ltd., India

Haas H (2014) Fungal siderophore metabolism with a focus on Aspergillus fumigatus. Nat Prod Rep 31(10):1266-1276. https://doi.org/10.1039/c4 np00071d

Hafeez FY, Yasmin S, Ariani D, ur-Rahman M, Zafar Y, and Malik KA. (2006) Plant growth-promoting bacteria as biofertilizer. Agron Sustain Dev 26(2):143-150. https://doi.org/10.1051/agro:2006007

Hossain MM, Sultana F, Miyazawa M, Hyakumachi M (2014) The plant growthpromoting fungus Penicillium spp. GP15-1 enhances growth and confers protection against damping-off and anthracnose in the cucumber. J Oleo Sci 63(4):391-400. https://doi.org/10.5650/jos.ess13143

Imran M, labal A, Barasubiye T, Abulreesh HH, Samreen S, Monjed MK, Elbanna K (2020) Heavy metal tolerance among free-living fungi isolated from soil receiving long term application of wastewater. J Pure Appl Microbiol 14:157170. https://doi.org/10.22207/JPAM.14.1.17

Jahangeer S, Khan N, Jahangeer S, Sohail M, Shahzad S, Ahmad A, Khan SA (2005) Screening and characterization of fungal cellulases isolated from the native environmental source. Pak J Botany 37:739

Jalal MAF, van der Heim D (1990) Isolation and spectroscopic identification of fungal sidrophores. In: Winklemann G (ed) Handbook of Microbial Iron Chelates. CRC Press, pp 225-269

Khalil MI, Ramadan NA, Albarhawi RK (2013) Biodegradation of polymers by fungi isolated from plastic garbage and the optimum condition assessment of growth. Raf J Env 1:33-43

Krithika S, Chellaram C (2016) Isolation, screening, and characterization of chitinase producing bacteria from marine wastes. Int J Pharm Pharmac Sci 8: 34-36

Kumar CS, Jacob TK, Devasahayam S, Thomas S, Geethu C (2018) Multifarious plant growth promotion by an entomopathogenic fungus Lecanicillium psalliotae. Microbiol Res 207:153-160. https://doi.org/10.1016/.micres.2017.11.017

Li RX, Cai F, Pang G, Shen QR, Li R, Chen W (2015) Solubilisation of phosphate and micronutrients by Trichoderma harzianum and its relationship with the promotion of tomato plant growth. PLoS One 10(6):e0130081. https://doi. org/10.1371/journal.pone.0130081

Liaud N, Giniés C, Navarro D, Fabre N, Crapart S, Herpoël-Gimbert I, Sigoillot JC (2014) Exploring fungal biodiversity: organic acid production by 66 strains of filamentous fungi. Fungal Biol Biotechnol 1:1. https://doi.org/10.1186/s40694014-0001-z

Lindner BC, Harley CP (1942) A rapid for the determination of nitrogen in plant tissue. Science (Washington) 96(2503):565-566. https://doi.org/10.1126/ science.96.2503.565

Lowry OH, Rosebrough NJ, Farr AL, Randall RJ (1951) Protein measurement with the Folin phenol reagent. J Biol Chem 193(1):265-275. https://doi.org/10.101 6/S0021-9258(19)52451-6

Mandels M, Parrish FW, Reese ET (1962) Sophorose as an inducer of cellulase in Trichoderma viride. J Bacteriol 83:400-408

McKelvey SM, Murphy RA (2018) Biotechnological use of fungal enzymes. In: Kavangh K (ed) Fungi: Biology and Applications, 3rd edn. Wiley, New York, pp 201-225
Mohamed I, Eid KE, Abbas MH, Salem AA, Ahmed N, Ali M, Fang C (2019) Use of plant growth promoting Rhizobacteria (PGPR) and mycorrhizae to improve the growth and nutrient utilization of common bean in a soil infected with white rot fungi. Ecotoxicol Environ Saf 171:539-548. https://doi.org/10.1016/j. ecoenv.2018.12.100

Nampally M, Rajulu MB, Gillet D, Suryanarayanan TS, and Moerschbacher BB. (2015) A high diversity in chitinolytic and chitosanolytic species and enzymes and their oligomeric products exist in soil with a history of chitin and chitosan exposure. Biomed Res Int 2015: Article ID 857639. DOI: https://doi. org/10.1155/2015/857639

Newbound M, Mccarthy MA, Lebel T (2010) Fungi and the urban environment: a review. Landsc Urban Plan 96:138-145. https://doi.org/10.1016/j.landurbplan.2 010.04 .005

Ogbonna CN, Okpokwu NM, Okafor CU, Onyia CE (2014) Isolation and screening of amylase producing fungi obtained from garri processing site. Int J Biotechnol Food Sci 2:88-93

Osman GEH, Already R, Assaeedi ASA, Organji SR, El-Ghareeb D, Abulreesh HH, Althubiani AS (2015) Bioinsecticide Bacillus thuringiensis a comprehensive review. Egypt J Biolo Pest Control 25:271

Park HS, Jun SC, Han KH, Hong SB, Yu JH (2017) Diversity, application, and synthetic biology of industrially important Aspergillus fungi. Adv Appl Microbiol 100:161-202. https://doi.org/10.1016/bs.aambs.2017.03.001

Patel D, Patel S, Thakar P, Saraf M (2017) Siderophore producing Aspergillus spp as bioinoculant for enhanced growth of mung bean. Int J Adv Agricult Sci Technol 6(1):111-120. https://doi.org/10.23953/cloud.ijaast.229

Premono ME, Moawad AM, Vlek PLG (1996) Effect of phosphate-solubilizing Pseudomonas putida on the growth of maize and its survival in the rhizosphere. Indonesian J Crop Sci 11:13-23

Prusky D, McEvoy JL, Leverentz B, Conway WS (2001) Local modulation of host $\mathrm{pH}$ by Colletotrichum species as a mechanism to increase virulence. Molec Plant-Microbe Interact 14(9):1105-1113. https://doi.org/10.1094/MPMI.2001.14. 9.1105

Ram L, Kaur K, Sharma S (2014) Screening isolation and characterization of cellulase producing microorganisms from soil. Int J Pharmaceut Sci Invent 3: $12-18$

Rani N, Jain P (2017) Isolation of antimicrobial compound producing fungi from the rhizospheric soil of the medicinal plant Azadirachta indica. J Chem Pharm Res 9:265-270

Rathore AS, Gupta RD (2015) Chitinases from bacteria to human: properties, applications, and future perspectives. Enzyme Res 2015:Article ID 791709. https://doi.org/10.1155/2015/791907

Reddy PLN, Babu BS, Radhaiah A, Sreeramulu A (2014) Screening, identification and isolation of cellulolytic fungi from soils of Chittoor district, India. Int J Curr Microbiol App Sci 3:761-771

Rekha V, Saifuddin MD, Ahammad SR, Dhal PK (2013) Isolation of amylase producing fungi from paddy-field soil. Ecol Environ Conserv 19:1041-1044

Saxena J, Pant V, Sharma MM, Gupta S, Singh A (2015) Hunt for cellulase producing fungi from soil samples. J Pure Appl Microbiol 9:2895-2902

Scervino JM, Mesa MP, Della MI, Recchi M, Moreno NS, Godeas A (2010) Soil fungal isolates produce different organic acid patterns involved in phosphate salts solubilization. Biol Fertil Soils 46:755-763. https://doi.org/10.1007/s003 74-010-0482-8

Shah S, Shrestha R, Maharjan S, Selosse MA, Pant B (2019) Isolation and characterization of plant growth-promoting endophytic fungi from the roots of Dendrobium moniliforme. Plants 8:5. https://doi.org/10.3390/plants8010005

Shaw S, Le Cocq K, Paszkiewicz K, Moore K, Winsbury R, de Torres ZM, Grant MR (2016) Transcriptional reprogramming underpins enhanced plant growth promotion by the biocontrol fungus Trichoderma hamatum GD12 during antagonistic interactions with Sclerotinia sclerotiorum in soil. Mol Plant Pathol 17(9):1425-1441. https://doi.org/10.1111/mpp.12429

Singh M, Singh D, Gupta A, Pandey KD, Singh PK, Kumar A (2019) Plant growth promoting rhizobacteria: application in biofertilizers and biocontrol of phytopathogens. In: Singh AK, Kumar A, Singh PK (eds) PGPR Amelioration in Sustainable Agriculture: Food Safety and Environmental Management. Woodhead Publishing, Sawston, pp 41-66. https://doi.org/10.1016/B978-0-12815879-1.00003-3

Singh S, Singh S, Bali V, Sharma L, Mangla J (2014) Production of fungal amylases using cheap, readily available agriresidues, for potential application in textile industry. Biomed Res Int 2014:Article ID 215748. https://doi.org/10.1155/2 014/215748 
Teather RM, Wood PJ (1982) Use of Congo red-polysaccharide interactions in enumeration and characterization of cellulolytic bacteria from the bovine rumen. Appl Environ Microbiol 43(4):777-780. https://doi.org/10.1128/a em.43.4.777-780.1982

Veliz EA, Martínez-Hidalgo P, Hirsch AM (2017) Chitinase-producing bacteria and their role in biocontrol. AlMS Microbiol 3:689. https://doi.org/10.3934/ microbiol.2017.3.689

Verma P, Verma RK (2018) Qualitative estimation of amylase enzyme activity of fungal species isolated from iron ore mined overburden soil. Trop Plant Res 5:396-404. https://doi.org/10.22271/tpr.2018.v5.13.049

Wadia T, Jain SK (2017) Isolation, screening and identification of lipase producing fungi from oil contaminated soil of Shani Mandir Ujjain. Int J Curr Microbiol App Sci 6:1872-1878. https://doi.org/10.20546/ijcmas.2017.607.223

Wahid OAA, Mehana TA (2000) Impact of phosphate-solubilizing fungi on the yield and phosphorus-uptake by wheat and faba bean plants. Microbiol Res 155(3):221-227. https://doi.org/10.1016/s0944-5013(00)80036-1

Wakelin SA, Gupta W, Harvey PR, Ryder MH (2007) The effect of Penicillium fungi on plant growth and phosphorus mobilization in neutral to alkaline soils from southern Australia. Can J Microbiol 53(1):106-115. https://doi.org/10.113 9/w06-109

Wösten HA (2019) Filamentous fungi for the production of enzymes, chemicals and materials. Curr Opin Biotechnol 59:65-70. https://doi.org/10.1016/j. copbio.2019.02.010

Xiao C, Chi R, He H, Qiu G, Wang D, Zhang W (2009) Isolation of phosphatesolubilizing fungi from phosphate mines and their effect on wheat seedling growth. Appl Biochem Biotechnol 159:330-342. https://doi.org/10.1007/s1201 0-009-8590-3

Yarrow D (1998) Methods for the isolation, maintenance and identification of yeasts. In: The Yeasts. Elsevier B.V., Amsterdam, pp 77-100

Zafar S, Ahmad I (2005) Fungal diversity of metal contaminated agricultural soils and in vitro fungi-toxicity of heavy metals. Pollut Res 24:793

Zhao L, Wang Q, Xiong S (2014) Identification of a fungus able to secrete enzymes that degrade regenerated cellulose films and analyses of its extracellular hydrolases. Ann Microbiol 64:1041-1048. https://doi.org/10.1007/ s13213-013-0741-7

Zhou LS, Tang K, Guo SX (2018) The plant growth-promoting fungus (PGPF) Alternaria sp. A13 markedly enhances Salvia miltiorrhiza root growth and active ingredient accumulation under greenhouse and field conditions. Int J Mol Sci 19:270. https://doi.org/10.3390/ijms19010270

\section{Publisher's Note}

Springer Nature remains neutral with regard to jurisdictional claims in published maps and institutional affiliations.

Ready to submit your research? Choose BMC and benefit from:

- fast, convenient online submission

- thorough peer review by experienced researchers in your field

- rapid publication on acceptance

- support for research data, including large and complex data types

- gold Open Access which fosters wider collaboration and increased citations

- maximum visibility for your research: over $100 \mathrm{M}$ website views per year

At BMC, research is always in progress.

Learn more biomedcentral.com/submissions 